\title{
MASTER \\ RESULTS FROM THE RUN-BEYOND-CLADDING-BREACH IRRADIATION OF A PREDEFECTED FUEL PIN (RBCB-7)
}

\section{Hanford Engineering Development Laboratory \\ D.C. Langstaff \\ M.Y. Almassy \\ D.F. Washburn}

This book was preared as an account of vork soonsored br an agency of the United States Government.

February 1980

iveither the United States Government nor ony agency thereot, nor ony of their empiovees, makes any

warraniv. express or implied. Or assumes any legal tiacility or responsibility for the accuracy

compleieness. or usetulness of any information, apparatus, product, or process disclosed.

reoresents itrat its use would not infringe privately ownud rights. Reference herein to any specilic

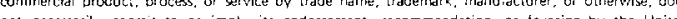

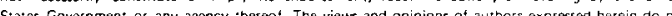

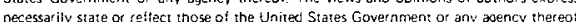




\section{DISCLAIMER}

This report was prepared as an account of work sponsored by an agency of the United States Government. Neither the United States Government nor any agency Thereof, nor any of their employees, makes any warranty, express or implied, or assumes any legal liability or responsibility for the accuracy, completeness, or usefulness of any information, apparatus, product, or process disclosed, or represents that its use would not infringe privately owned rights. Reference herein to any specific commercial product, process, or service by trade name, trademark, manufacturer, or otherwise does not necessarily constitute or imply its endorsement, recommendation, or favoring by the United States Government or any agency thereof. The views and opinions of authors expressed herein do not necessarily state or reflect those of the United States Government or any agency thereof. 


\section{DISCLAIMER}

Portions of this document may be illegible in electronic image products. Images are produced from the best available original document. 
HEDL-TME 79-62

UC-79b, $h$

RESULTS FROM THE RUN-BEYOND-CLADDING-BREACH

IRRADIATION OF A PREDEFECTED FUEL PIN (RBCB-7)

D. C. Langstaff,

M. Y. Almassy and

D. F. Washburn

\section{ABSTRACT}

A slit was machined through the cladding of an irradiated fuel pin and irradiation in the Experimental Breeder Reactor-II (EBR-II) was resumed. The condition of the fuel pin was continuously followed with delayed neutron (DN) monitors. When the DN signal increased to a previously estabIished administrative limit of 800 counts per second, the test was terminated. Postirradiation examination showed the sodium-fuel reaction caused fuel pin swelling and extension of the machined slit. There was no evidence of fuel washout nor was there any indiction of impending pin-to-pin failure propagation. This test supports an increase in DN signal for subsequent run-beyond-cladding-breach (RBCB) tests. 


\section{ACKNOWLEDGEMENTS}

The authors would like to take this opportunity to express their appreciation and thanks to the many people who aided in the preparation, conduct and examination of this irradiation test. In particular we would like to thank J. P. Bacca, R. D. Phipps, G. O. Hayner and the HFEF/N cell operators who were responsible for machining the cladding slit, disassembling the subassembly and aiding in fuel pin examination; J. I. Sackett and his staff at EBR-II for their concerted effort in obtaining the necessary approvals for irradiation of the test; $Y$. Harker and I. Steffan of EG\&G Idaho, Inc. for the ir efforts in completing the fissile assay; J. D. Berger and T. T. Arey (HEDL) for their efforts in coordinating the activities at the Idaho National Engineering Laboratory; and L. A. Pember and his postirradiation testing laboratory staff for their diligence in conducting the destructive examination of the fuel pin. 


\section{CONTENTS}

Page

Abstract

i i i

Acknow ledgements

iv

Figures

vij

Tables

ix

I. SUMMARY AND CONCLUSIONS 1

II . INTRODUCTION 3

III. TEST DESIGN AND DESCRIPTION

A. TEST DESIGN 5

B. FABRICATION DATA FOR FUEL PIN 9

C. PRIOR IRRADIATION HISTORY AND FUEL PIN CONDITION 12

D. CLADDING DEFECTING PROCEDURE AND DEFECT APPEARANCE 12

$\begin{array}{ll}\text { E. SUBASSEMBLY LOADING } & 16\end{array}$

$\begin{array}{lll}\text { F. TEST TERMINATION CRITERION } & 21\end{array}$

IV. RBCB-7 IRRADIATION HISTORY 23

V. POSTIRRADIATION EXAMINATION 29

A. SUBASSEMBLY DISMANTLING 29

B. VISUAL EXAMINATION 32

C. GAMMA SCAN 35

D. FISSILE ASSAY 35

E. FUEL PIN SWELLING 39

F. NEUTRON RADIOGRAPHY 41

G. FUEL PIN SHIPMENT 41

H. FUEL PIN DESTRUCTIVE EXAMINATION 41 


\section{CONTENTS (Cont'd)}

Page

1. Fuel Pin Sectioning

2. Ceramography

3. Water Wash Sample

4. Fuel Pin Cladding

44

44

58

59

VI. DISCUSSION

61

A. RBCB AT CONSTANT POWER 62

B. RBCB WITH POWER CHANGES - 66

C. FUEL AND FISSION PRODUCT LOSSES 67

VII. CONCLUSIONS 69

VIII. REFERENCES 


\section{FIGURES}

Figure

$\underline{\text { Page }}$

1 Loading Diagram for the SLSF-1 (X224) Subassembly 6

2 Loading Diagram for the SLSF-2 (X225) Subassembly 7

3 Loading Diagram for the SLSF-3 (X226) Subassembly 8

4 Design of Fuel Pins Used in RBCB-7 10

5 Gross Gamma-Scan for ZP-5-42 Prior to RBCB Irradiation 15

6 Intentional Cladding Defect, As-Machined, Showing Good Fuel Exposure at the Bottom of the Slit 17

7 Loading Diagram for RBCB-7 20

8 Reactor Power and Delayed Neutron Signal Time History During RBCB-7, EBR-II Run 90A 24

9 Delayed Neutron Signal from RBCB-7 Increased Nonlinearly with Reactor (or Pin) Power 25

10 The Average Delayed Neutron Signal Increased Continuously Until the Administrative Shutdown Limit was Reached

11 VAD Filter Installed to Investigate a Potential Spread of Pu Contamination from an RBCB Subassembly During Forced Cooling

12 Appearance of Sodium Remaining on the RBCB-7 Breached Pin (ZP-5-42): a) Under the Wire Wrap, b) Globules, C) 'Powdered Sugar'

13 The Breach Appearance of RBCB-7 (ZP-5-42): a) AsFabricated and Post-RBCB Irradiation; b) at HFEF/N and c) at HEDL (As-Received) After Filling the Breach with Resin and Shipping from $\mathrm{HFEF} / \mathrm{N}$

14 Gross Gamma Scan for ZP-5-42 after RBCB Irradiation 36

15 Cesium Gamma Scan for ZP-5-42 Before and After RBCB Irradiation

16 Fissile Assay Reactivity Data for RBCB-7 (ZP-5-42) 
FIGURES (Cont'd)

Figure

Page

17 Diameter of RBCB-7 Fue 1 Pin ZP-5-42 Before and After

RBCB Irradiation

40

18 Radiography of Two Predefected Fuel Pins after RBCB Operation: a) Betatron Radiograph Showing the Breached Area of RBCB-6 (ZP-8-24), b) Neutron Radiograph Showing the Breach Area of RBCB-7 (ZP-5-42) and c) Neutron Radiograph Showing the Unfailed Fuel Pin $(\mathrm{ZP}-5-34)$.

19 A Sumary of the Photomicrography for ZP-5-42 43

20 Microstructure of HEDL-ZP-5-42 Sample L 45

21 Microstructure of HEDL-ZP-5-42 Sample L - Radial Strips

22 Microstructure of HEDL-ZP-5-42 Sample $J$

23 Microstructure of HEDL ZP-5-42 Sample J - Radial Strips

24 Microstructure of HEDL-ZP-5-42 Sample J - Radial Strips

25 Microstructure of HEDL-ZP-5-42 Sample $H$

26 Microstructure of HEDL-ZP-5-42 Sample E 51

27 Microstructure of HEDL-ZP-5-42 Sample E - Radial Strip

28 Transition Zone in the Fuel from ZP-5-42 Sample $H$ Showing Transition in Fue 1. Structure and Morphology of Sodium-Fuel Reaction Product

29 Transition Zone in the Fuel from ZP-5-42 Sample $\mathrm{H}$ Showing the Transition in Fuel Structure and Morphology of the Sodium-Fuel Reaction Product Along a Radial Fuel Crack

30 Sodium-Fuel Reaction Proaict Morphology Around Pores in the Dense Outer Fuel Ring and Inner Fuel Core Areas of ZP-5-42 Sample $H$ 


\section{FIGURES (Cont'd)}

Figure

31 Sodium-Fuel Reaction Product Morphology Around a Pore Bridging the Abrupt Transition in Fuel Structure of ZP-5-42 Sample H

32 Cladding Fracture Profile from ZP-5-42 Sample J

33 Schematic Diagram Illustrating the Terms Used to

Describe the Sodium-Fuel Reaction Product Distribution:

a) Fuel Structure and b) Reaction Depth

\section{TABLES}

Table

Page

1 Subassembly Core Locations

2 Fue 1 Pin Design Parameters

3 End of Irradiation Summary for Pin ZP-5-42

4 End of Irradiation Sumary for Pin with Peak Midwall Cladding Temperature

5 Fuel Pins Irradiated in $\times 310$

6 Irradiation Information

$7 \quad$ ZP-5-42 In-Cel1 Smear Survey Data

$8 \quad \mathrm{RBCB}-7$ Cladding Defect Dimensions 
RESULTS FROM THE :RUN-BEYOND-CLADDING-BREACH IRRADIATION OF A PREDEFECTED FUEL PIN (RBCB-7) (FF021)

\section{SUMMARY AND CONCLUSIONS}

A mixed-oxide fuel pin at a burnup of 6.3 atom percent (at.\%) was defected by machining a slit through the cladding. The area of the slit was $0.35 \mathrm{~cm}^{2}$. No attempt was made to seal the slit after machining. The predefected fuel pin experienced two reactor startups before reaching full power and operating for two and one-half hours in Experimental Breeder Reactor-II (EBR-II). The delayed neutron (DN) signal increased nonlinearly during the power increases. The administrative test termination criterion of 800 counters per second DN signal was established during the first reactor startup. The DN signals during the second reactor startup were generally higher for the same reactor power than those during the first startup. During steady-state irradiation, the DN signal slowly but continuously increased until the administrative shutdown limit was reached.

Sodium-fuel reaction caused the cladding slit to extend in both directions. However, the slit did not extend much beyond the top end of the fuel column but was predominantly in the downward direction over the fuel. There was no visual indication of fuel washout through the cladding defect. The test pin diameter increase was less than 5 percent and there was no indication of impending pin-to-pin failure propagation.

The fuel pin was shipped from the Hot Fuel Examination Facilities (HFEF) to Hanford Engineering Development Laboratory (HEDL) with no apparent change in fuel condition. The effects of shipping were of concern because of the significant increase in pin diameter and change in breach appearance during shipping of the run-beyond-cladding-breach (RBCB)-6 predefected fuel pin.

Sodium-fuel reaction occurred primarily over the upper third of the fuel column. The intergranular reaction was confined to the outer fuel rim, generally beyond a radius of $2.1 \mathrm{~mm}$ in a ring $0.4 \mathrm{~mm}$ to $0.6 \mathrm{~mm}$ thick. 
Isolated rounded islands of reaction product were also observed in the outer rim, but were more common in the inner fuel core.

This test provided additional operational experience with an RBCB fuel pin. The DN signal increased with increasing fission rate (reactor power) but remained stable when the power level (fission rate) was held constant. This indicated a stable breach condition while the reactor was held at intermediate power levels. However, a gradually increasing DN signal indicated a slowly changing fuel pin condition during steady-state irradiation at full reactor power. The rate of reaction-induced cladding crack extension was slow enough to allow reactor operators to take action to preclude the development of a safety hazard. There was no indication that any safety hazard was developing as a result of the RBCB-7 irradiation. The results from this test will be used to support higher DN signal limits during irradiation of subsequent RBCB tests. 


\section{INTRODUCTION}

A sequence of mixed-oxide fuel pin RBCB tests was run in EBR-II to provide operating experience to support the post-breach irradiation of mixed-oxide fue 1 pins in a sodium-cooled fast breeder reactor (FBR).

The RBCB-7 test provided a second data point during calibration of the DN detection system. The objectives of the RBCB-6 and -7 predefected pin tests were to provide an early indication of the effects of the sodium-fuel reaction on fuel pin performance and to relate the DN signals in EBR-II to the size of the breach so that premature removal of breached fuel pins can be avoided.

In general, the RBCB tests were designed to:

1) demonstrate the benign behavior of a breached pin during steady-state operation,

2) demonstrate that plutonium release from the fuel into the reactor coolant would result in a plutonium concentration in the sodium of less than 100 parts-per-billion,

3) provide breached fuel pins for transient testing.

It is difficult to develop an expedient schedule for RBCB tests with naturally occurring in-reactor breaches because of their unpredictable occurrence in a fue 1 development program. The major interest in RBCB fuel pin behavior is with naturally occurring breaches because they are considered prototypic of reactor operation. However, tests using irradiated mixed-oxide fuel pins with defects machined through the cladding (RBCB-6 and -7) could achieve two objectives: 1) provide information on the in-reactor sodium-fuel reaction and 2) provide previously unavailable calibration data for EBR-II fissionproduct monitors, especially the DN detectors.

Prior to initiating the RBCB irradiation testing program in EBR-II, several safety and operational questions were resolved. $(1,2,3)$ DN monitors, the 
primary method for monitoring fuel exposed to coolant, were calibrated with a fission product source ${ }^{(4)}$ and predefected $\mathrm{UO}_{2}$ elements. ${ }^{(5)}$

This report describes the results of the second predefected fuel pin test, RBCB-7. The first test of a predefected, mixed-oxide fue 1 pin was designated RBCB-6. ${ }^{(6)}$ These defected fue 1 pins were irradiated individually in EBR-II until test termination was required because of administrative DN signal limits. Despite the fact that the predefected fuel pin tests were not prototypic of RBCB pins with breaches that occur naturally, they did provide a mixed-oxide DN source for calibration of the DN detection system. Calibration of the DN detection system permitted less restrictive irradiation conditions for the naturally occurring in-reactor breached pins. The predefected pin tests also provided an opportunity to develop and demonstrate handling procedures for fuel pins with exposed fuel and examination procedures for fuel pins containing sodium. 


\section{TEST DESIGN AND DESCRIPTION}

\section{A. TEST DESIGN}

The predefected fuel pin tests were designed to investigate the effects of fuel burnup and defect size on the DN signal magnitude and the effect of fue 1 burnup on the sodium-fuel reaction. The test sequence consisted of two 37-pin subassemblies each containing one predefected fuel pin. The remaining 36 pins in both RBCB-6 ${ }^{(6)}$ and -7 served as "drivers." Fabrication of these pins was avoided by using intermediate burnup pins from the Sodium Loop Safety Facility (SLSF)-1, -2 and -3 (X224, X225 and X226) subassemblies and two unirradiated spare pins (Figures 1, 2 and 3). These SLSF subassemblies were similar in the ir irradiation conditions and all contained fuel pins with burnups ranging from approximately $50 \mathrm{MWd} / \mathrm{kg}$ to $80 \mathrm{MWd} / \mathrm{kg}$. These pins, originally scheduled for use in the SLSF tests, would not be adversely affected by irradiation in the RBCB tests even though they could undergo as much as 1 at.\% additional burnup.

The reactor core location for irradiation of RBCB-7 was comparable to that of the SLSF subassemblies (Tabie 1). The core location for RBCB-7 was selected to minimize the potential effects of changing core location on fuel pin performance.

TABLE 1

SUBASSEMBLY CORE LOCATIONS

$\begin{array}{lcc}\begin{array}{c}\text { Test } \\ \text { Name }\end{array} & \begin{array}{c}\text { Subassembly } \\ \text { Designation }\end{array} & \begin{array}{c}\text { Core } \\ \text { Location }\end{array} \\ \text { RBCB-7 } & \times 310 & 6 \text {. } \\ \text { SLSF-1 } & \times 224 & 6 \mathrm{E} 2 \\ \text { SLSF-2 } & \times 225 & 6 C 2 \\ \text { SLSF-3 } & \times 226 & 6 E 2\end{array}$




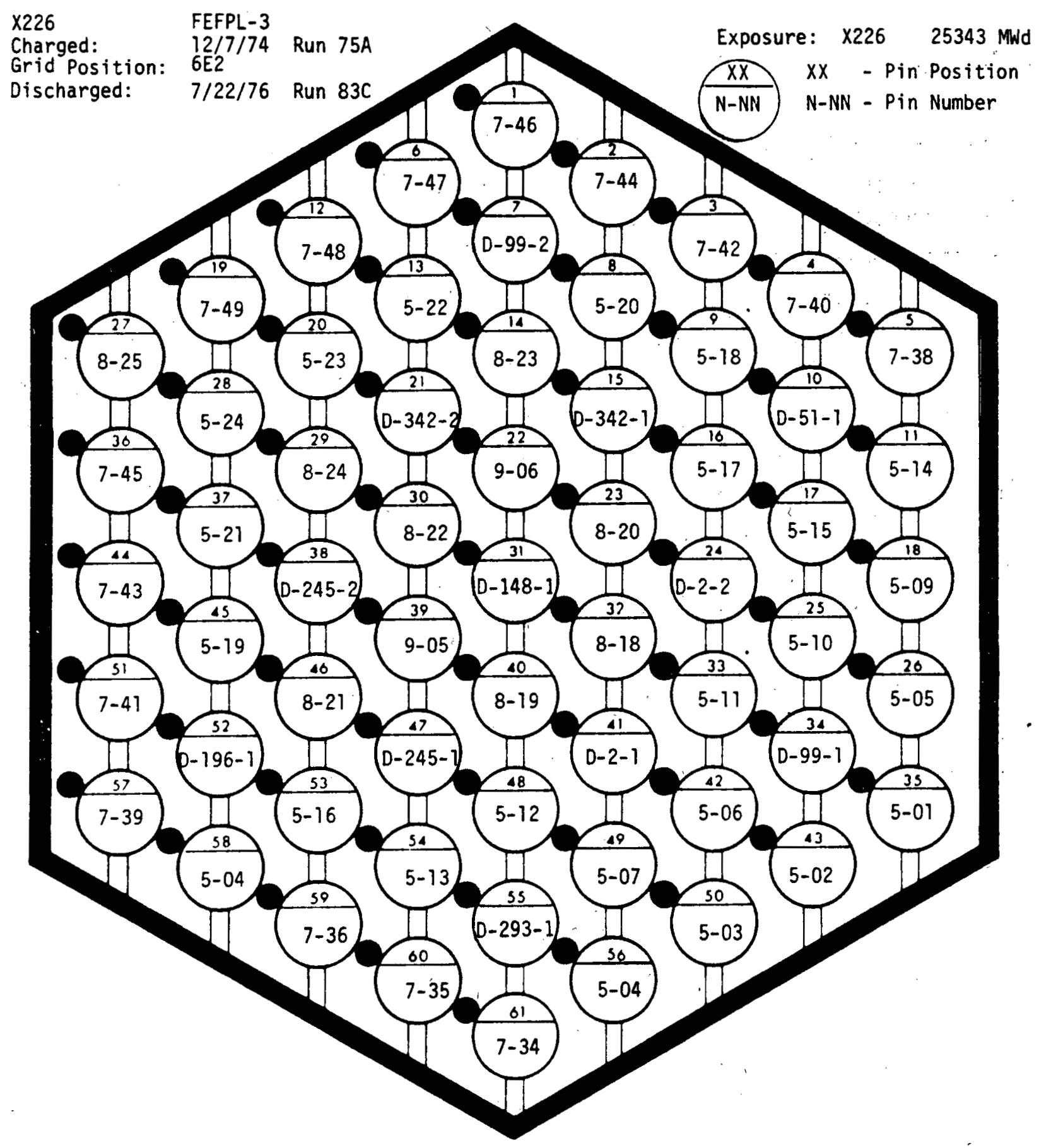

FIGURE 1. Loading Diagram for the SLSF-1 (X224) Subassembly. 


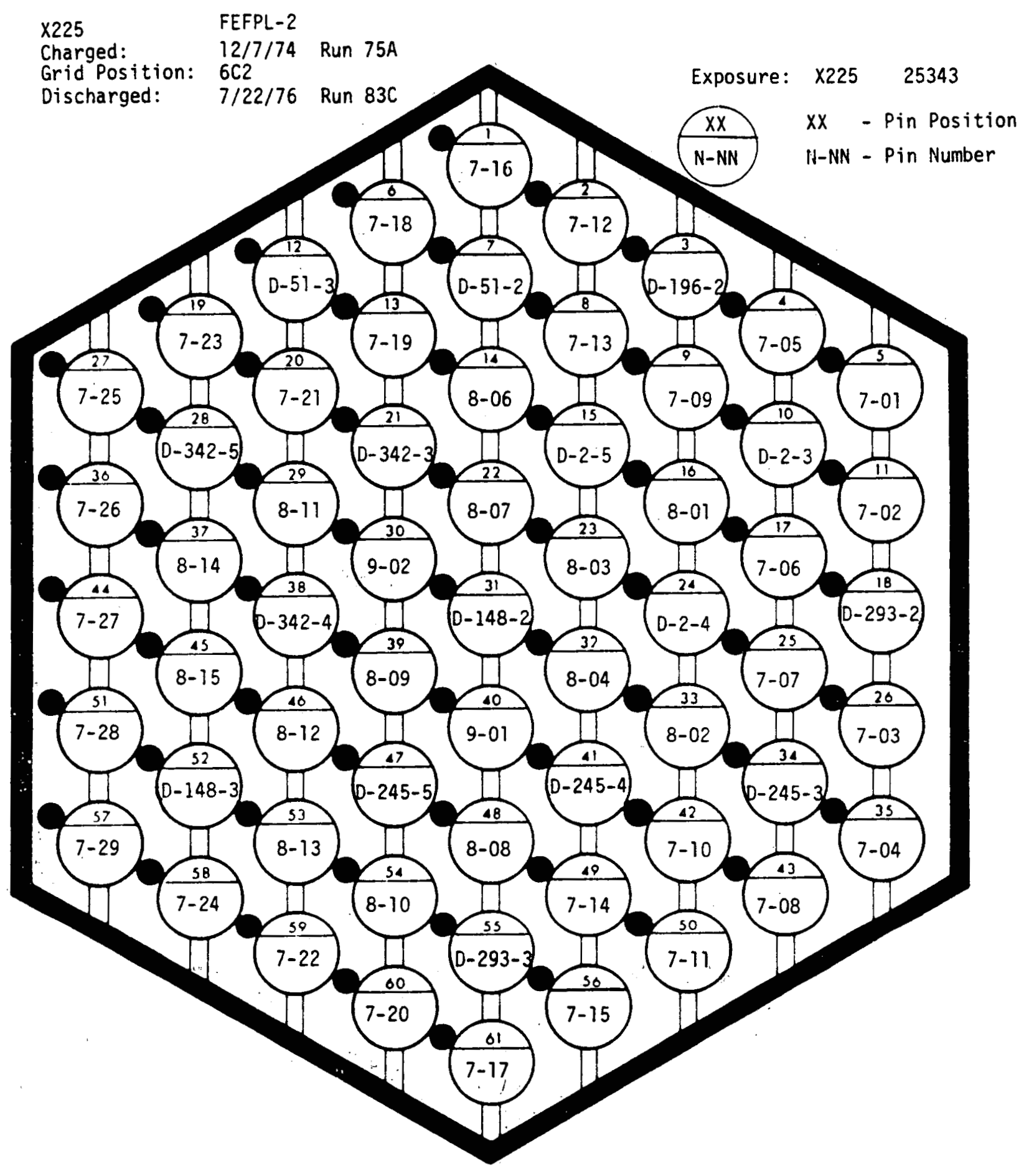

FIGURE 2. Loading Diagram for the SLSF-2 (X225) Subassembly. 


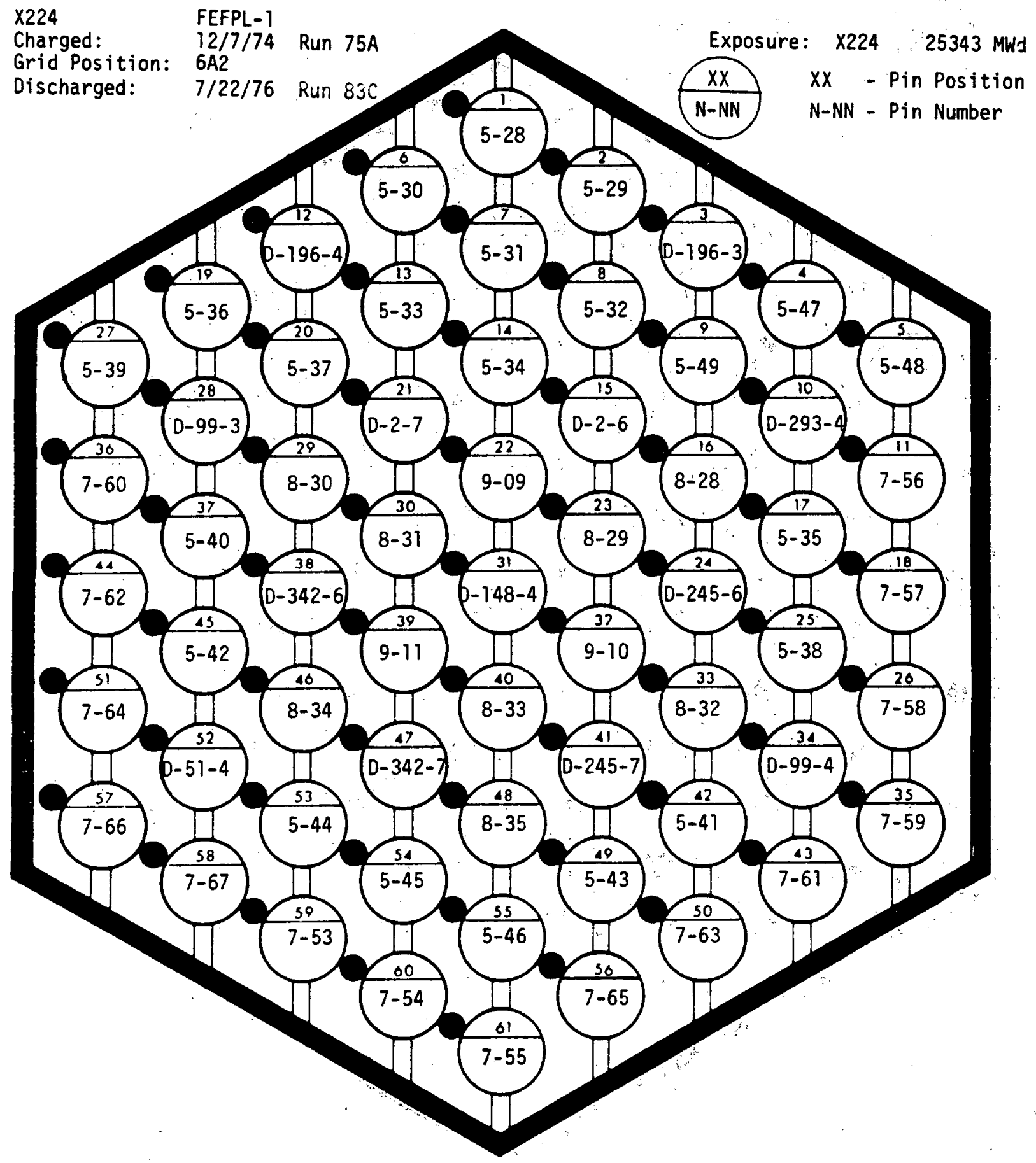

FIGURE 3. Loading Diagram for the SLSF-3 (X226) Subassembly. 
The irradiation of the predefected fuel pins was intentionally limited to one EBR-II run to avoid conflicting with the higher priority end-of-life RBCB tests.

Several factors were considered when establishing the size and location of the machined cladding defects. The most frequent breach location observed in the run-to-cladding-breach test examinations was in the upper third of the fuel column. Naturally occurring breaches were predominantly pinhole breaches that leaked fission gases but were small enough to prevent coolant access to the fuel. Therefore, an intentionally produced defect would start with a larger initial size than a naturally occurring cladding breach. Moreover, it is almost certain that immediate sodium ingress will occur in any size of machined defect. It was recognized that this might detract from the prototypicality of the observations on the sodium-fuel reaction itse if and its effects on the pin performance. However, predefected pins can provide calibration points relating defect size to DN signal magnitude. At the time, there was no correlation between DN signal and cladding breach size. It was desirable, therefore, to test predefected fuel pins with large defect areas yielding DN signals of sufficiently differing magnitudes to be useful in establishing a correlation. However, it was also reasonable to limit their size until additional RBCB experience was developed.

\section{B. FABRICATION DATA FOR FUEL PIN}

The predefected fuel pin contained 75\% U-25\% Pu mixed-oxide fuel in 5.84-mm (0.230-in.) OD $20 \% \mathrm{CW} 316 \mathrm{SS} \mathrm{cladding}$ with a $0.38-\mathrm{mm}(0.015-i n$.$) wall thick-$ ness and was $154.5 \mathrm{~cm}$ (60.81 inches) in overall length. The uranium was $58 \%$ enriched in ${ }^{235} \mathrm{U}$ and the fue $10 / \mathrm{M}$ was 1.96 . The pin geometry and dimensions are detailed in Figure 4. Additional design parameters are listed in Table 2. 


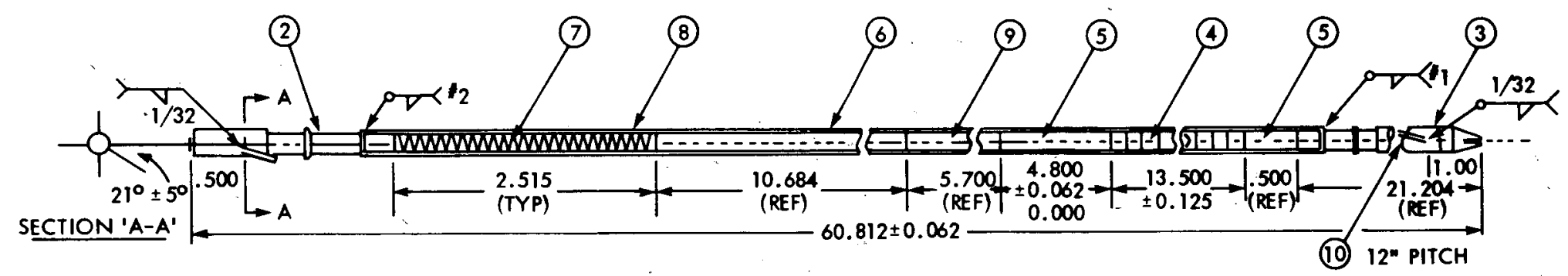

$\vec{o}$
(1) ASSEMBLY
(6) PLENUM SPACER
(2) END CAP (TOP)
(7) SPRING-COMPRESSION
(3) END CAP (BOTTOM)'
(8) TUBING
(4) FUEL PELLET
(5) INSULATOR PELLET
(9) REFLECTOR
(10) WIRE WRAP

FIGURE 4. Design of Fuel Pins Used in RBCB-7. 
TABLE 2

FUEL PIN DESIGN PARAMETERS

Fue 1

Fue 1 Composition Pu/Pu+U

Uran ium Enr ichment

Plutonium Enrichment

Fuel Pellet Diameter

Fue I Pellet Geometry

Dish Depth

Fue 1 Column Length

Fue 1 Pellet $0 / M$

Fuel Pellet Theoretical Density (TD)

Fuel Pellet Density

Fue 1 Smeared Density

Fue 1 Column We ight

Natura $1 \mathrm{UO}_{2}$ Column -- total length

Cladding Material

Cladding Cond ition

Cladding Dimensions

Wire Wrap Material

Wire Wrap Condition

Wire Wrap Diameter

Plenum Spring Material

Plenum Spacer Dimensions

Plenum Spacer Material

Gas Plenum Volume (nominal)

Plenum Gas

Plenum Gas Presssure at Room Temperature

Reflector Material

Reflector Dimensions

Reflector Volume (nominal)

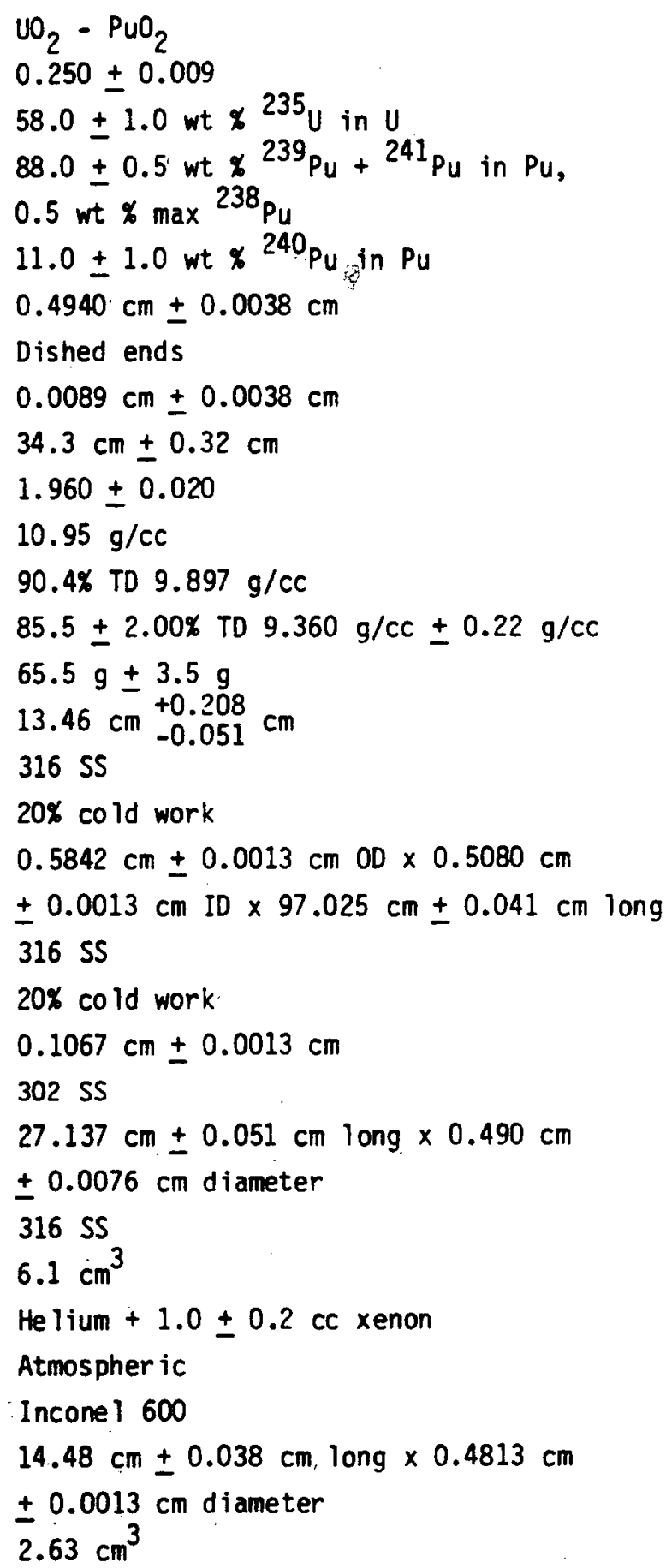




\section{PRIOR IRRADIATION HISTORY AND FUEL PIN CONDITION}

Irradiation of the ZP-5-42 fuel pin was started in EBR-II Run 75A. The pin was contained in the 61 pin, SLSF-3 (X226) subassembly, with mixed-oxide fueled pins of different ${ }^{235} U$ enrichments and non-fueled dumy pins. The subassembly was in the 6E2 core location throughout irradiation. The irradiation continued through EBR-II Run $83 \mathrm{C}$ when $\mathrm{X} 226$ was moved from the reactor core to the core basket. The burnup of the ZP-5-42 pin was 6.3 at.\% and the cladding fluence was $5.3 \times 10^{22}$. neutron- $\mathrm{cm}^{-2}$. An irradiation sumary is shown in Table 3.

Fue 1 pins comprising the RBCB-7 (X310) subassemby were from the SLSF-1 (X224), SLSF-2 (X225) and SLSF-3 (X226) subassemblies. The subassembly hardware (MK-B-61A), complement of pins and irradiation histories of X224 and $X 225$ were similar to those of X226. All three began irradiation in EBR-II Run 75A. The ir irradiation continued through EBR-II Run 83C. Irradiation sumaries for the peak pin in each subassembly are listed in Table 4.

A postirradiation examination of $\mathrm{ZP}-5-42$ at $\mathrm{HFEF} / \mathrm{N}$ approximately one year after the removal of $X 226$ from the reactor showed that the condition of the pin was generally good. The wire wrap was loose and there were light discolorations and minor scratches on the cladding. Neutron radiography revealed a normal fuel and insulator structure. No central void had developed. The gross gamma scan was fairly typical (Figure 5). The peak at 38 inches was not further identified. Spiral profilometry revealed no anamalies. The maximum pin diameter increase was less than $0.013 \mathrm{~mm}$ (0.0005 in.).

\section{CLADDING DEFECTING PROCEDURE AND DEFECT APPEARANCE}

The defect was centered about $30 \mathrm{~mm}$ (1-1/4 inches) below the top of the fue 1 column. This location was representative of the location of naturally occurring breaches and allowed for a relatively long slit to be machined 
TABLE 3

\section{END OF IRRADIATION SUMMARY \\ FOR PIN ZP-5-42}

$\begin{array}{ll}\text { Subassembly Name } & \text { SLSF }-3 \\ \text { EBR-II Name } & \text { ZP-5-42 } \\ \text { Core Location } & 6 E 2 \\ \text { Ending EBR-II Run } & 83 C\end{array}$

\section{PEAK ENDING CONDITIONS}

$\begin{array}{ll}\text { Cumulative EFPD } & 405.0 \\ \text { Burnup (at.\%) } & 6.3 \\ \text { Burnup (MWd/MTM) } & 61425.0 \\ \text { Fluence }>0.1 \mathrm{MeV}\left(\mathrm{n} / \mathrm{cm}^{2}\right) & 5.31 \times 10^{22} \\ \text { Flux }>0.1 \mathrm{MeV}\left(\mathrm{n} / \mathrm{cm}^{2} / \mathrm{s}\right) & 1.52 \times 10^{15} \\ \text { Total Fluence }\left(\mathrm{n} / \mathrm{cm}^{2}\right) & 6.34 \times 10^{22} \\ \text { Total Flux }\left(\mathrm{n} / \mathrm{cm}^{2} / \mathrm{s}\right) & 1.79 \times 10^{15} \\ \text { Gas Release }(\%) & 93.3 \\ \text { Gas Re lease }\left(\mathrm{cm}^{3}\right) & 77.62 \\ \text { Plenum Pressure }(p s i g) & 586.0 \\ \text { Heat Rate (W/cm) } & 224.0 \\ \text { Coolant Temperature }\left({ }^{\circ} \mathrm{C}\right) & 529.0 \\ \text { Cladding OD Temperature }\left({ }^{\circ} \mathrm{C}\right) & 534.0 \\ \text { Cl adding ID Temperature }\left({ }^{\circ} \mathrm{C}\right) & 553.0 \\ \text { Fuel Surface Temperature }\left({ }^{\circ} \mathrm{C}\right) & 983.0 \\ \text { Fuel Core Temperature }\left({ }^{\circ} \mathrm{C}\right) & 1667.0\end{array}$


TABLE 4

END OF IRRADIATION SUMMARY

FOR PIN WITH PEAK MIDWALL CLADDING TEMPERATURE

$\begin{array}{llll}\text { Subassembly Name } & \text { SLSF-1 } & \text { SLSF-2 } & \text { SLSF-3 } \\ \text { Pin Number } & \text { ZP-5-24 } & \text { ZP-8-07 } & \text { ZP-8-31 } \\ \text { EBR-II Name } & \text { X224 } & \text { X225 } & \text { X226 } \\ \text { Core Location } & 6 A 2 & 6 C 2 & 6 E 2 \\ \text { Ending EBR-II Run } & 83 C & 83 C & 83 C\end{array}$

PEAK ENDING CONDITIONS

$\begin{array}{llll}\text { Cumulative EFPD } & 405.0 & 405.0 & 405.0 \\ \text { Burnup (at.\%) } & 5.8 & 8.6 & 8.3 \\ \text { Burnup (MWd/MTM) } & 56,567 & 83,401 & 80,386 \\ \text { Fluence }>0.1 \mathrm{MeV} \times 10^{-22}\left(\mathrm{n} / \mathrm{cm}^{2}\right) & 5.20 & 5.54 & 5.37 \\ \text { Flux }>0.1 \mathrm{MeV} \times 10^{-15}\left(\mathrm{n} / \mathrm{cm}^{2} / \mathrm{s}\right) & 1.50 & 1.53 & 1.53 \\ \text { Total Fluence } \times 10^{-22}\left(\mathrm{n} / \mathrm{cm}^{2}\right) & 6.17 & 6.56 & 6.41 \\ \text { Total Flux } \times 10^{-15}\left(\mathrm{n} / \mathrm{cm}^{2} / \mathrm{s}\right) & 1.77 & 1.81 & 1.81 \\ \text { Gas Release }(\%) & 82.1 & 96.9 & 96.4 \\ \text { Gas Release }\left(\mathrm{cm}^{3}\right) & 62.95 & 111.54 & 105.42 \\ \text { Plenum Pressure (psig) } & 507 & 539 & 787 \\ \text { Heat Rate (W/cm) } & 211 & 297 & 291 \\ \text { Coolant Temperature }\left({ }^{\circ} \mathrm{C}\right) & 554 & 541 & 533 \\ \text { Cladding 0D Temperature }\left({ }^{\circ} \mathrm{C}\right) & 559 & 548 & 539 \\ \text { Cladding ID Temperature }\left({ }^{\circ} \mathrm{C}\right) & 577 & 573 & 564 \\ \text { Fuel Surface Temperature }\left({ }^{\circ} \mathrm{C}\right) & 1022 & 942 & 948 \\ \text { Fuel Core Temperature }\left({ }^{\circ} \mathrm{C}\right) & 1729 & 1771 & 1717\end{array}$




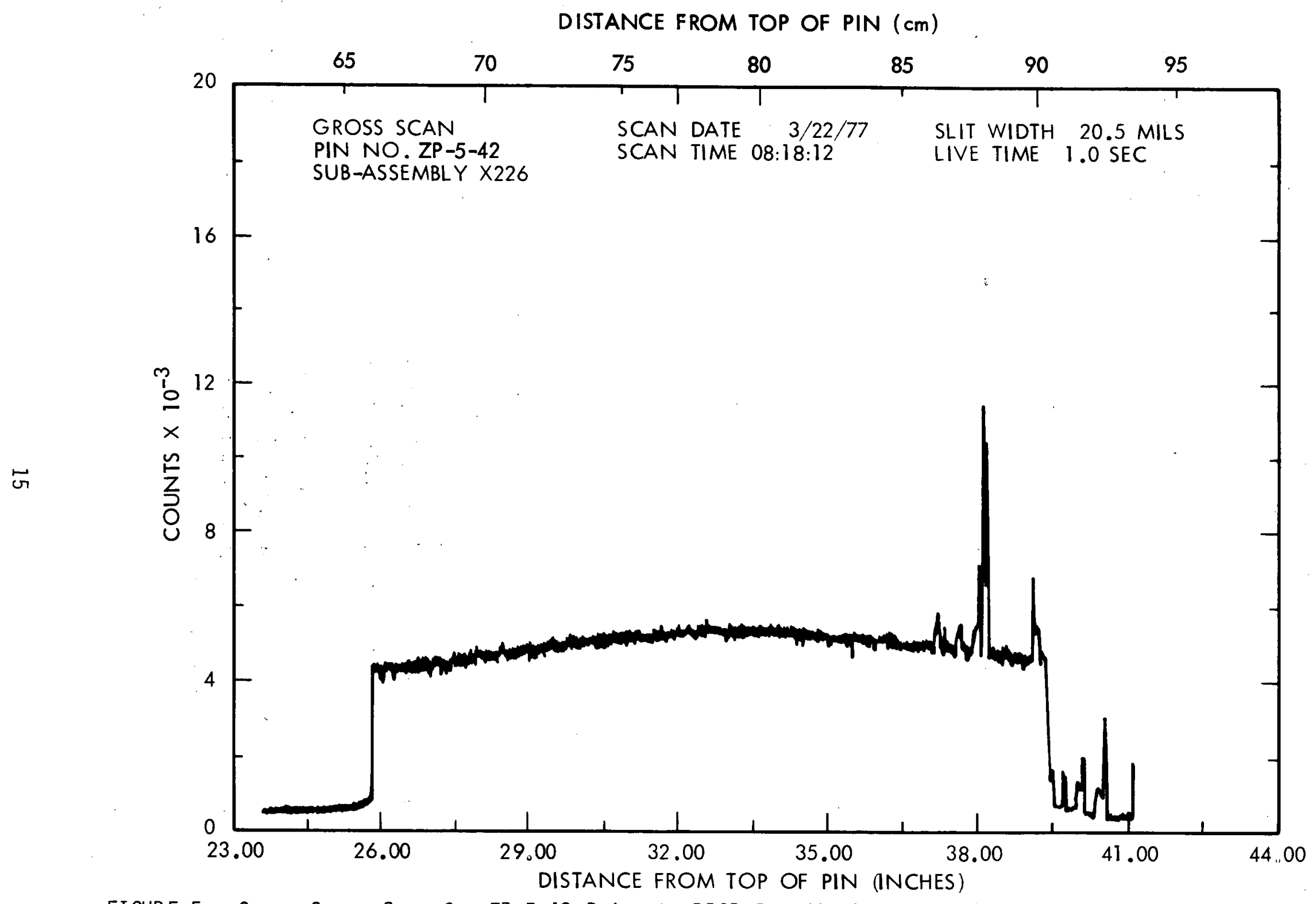

FIGURE 5. Gross Gamma-Scan for ZP-5-42 Prior to RBCB Irradiation. Neg 7909733-7 
through the cladding and not extend beyond the fuel column. The location also coincided with the slit location in the RBCB-6 fuel pin. (6)

The irradiated fuel pin was defected by maching a slit through the cladding with a specially designed slitting saw. (7). The location and length of the slit could be controlled but the slit width was dictated by the cutting whee 1 width. The slitting machine used a readily available diamondimpregnated cutting wheel, did not require blade coolant, did not contaminate the fuel or fuel pin and limited the spread of radioactive particles in the hot cell during the remote cutting operations.

The fuel pin was oriented so that the slit was opposite the wire wrap. The slit was $5.84 \mathrm{~cm}(2.30$ inches) 1 ong by $0.76 \mathrm{~mm}(0.030 \mathrm{in.})$ wide and was centered $30 \mathrm{~mm}$ (1-1/4 inches) below the top of the fuel column. The asmachined defect area was $0.35 \mathrm{~cm}^{2}$. Two separate machining attempts were required before good fuel exposure was observed along the bottom of the slit (Figure 6). The slit was machined in the inert argon atmosphere of HFEF/N. No attempt was made to plug the defect after it was machined.

\section{E. SUBASSEMBLY LOADING}

The RBCB-7 (X310) subassembly used MK-E-37D subassembly hardware and was loaded in HFEF/N. The RBCB-7 fue 1 pins and the previously irradiated subassembly are listed in Table 5. All the fuel pins except two, ZP-5-38 and ZP-5-51, were from subassemblies X224, X225 and X226. ZP-7-38 was originally irradiated in the RBCB-6 (X309) subassembly. ZP-5-51 was a fresh pin initially irradiated in the RBCB-6 (X309) subassembly.

Fue 1 pin bow ranged from slight to severe $(0.1 \mathrm{~cm}$ to $4.0 \mathrm{~cm})$ in the SLSF subassemblies. Special consideraton of pin bow led to the loading plan for X310 (Figure 7), which was devised to minimize the potential effects of pin bow on subassembly performance. 


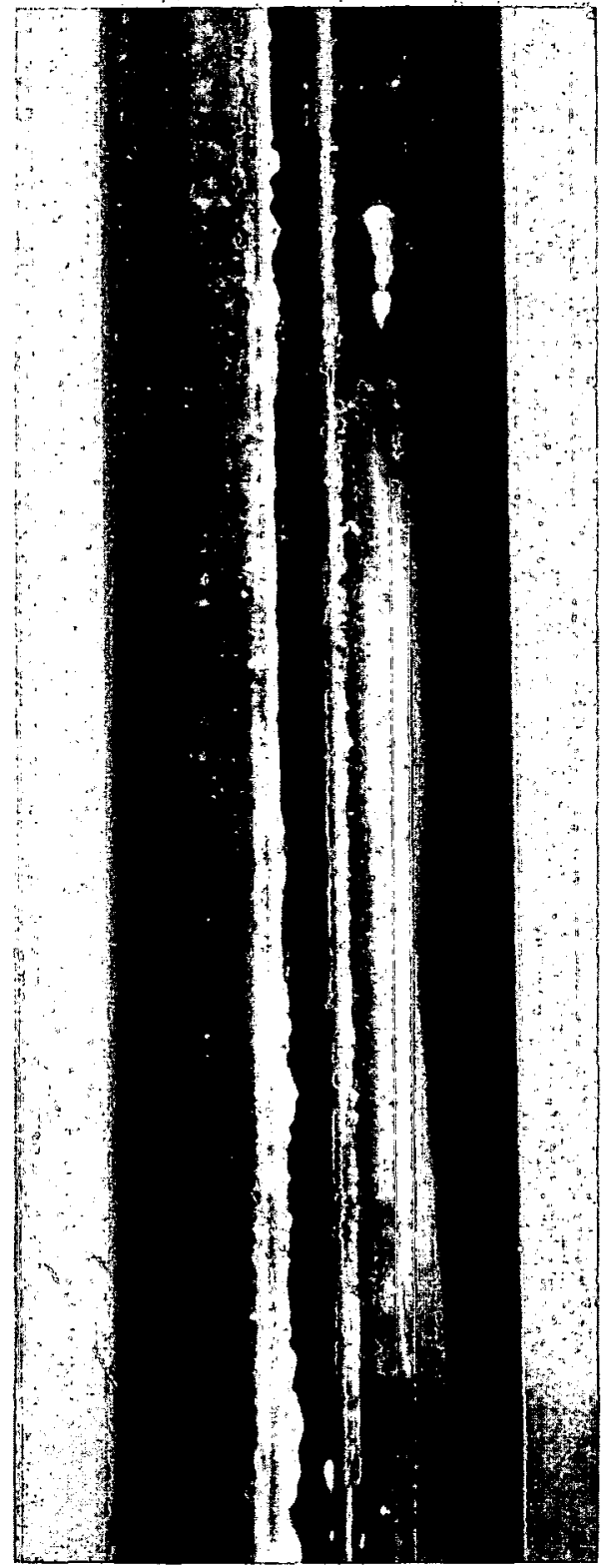

FIGURE 6. Intentional Cladding Defect, As-Machined, Showing Good Fue 1 Exposure at the Bottom of the Slit. Neg 7909733-16 
TABLE 5

FUEL PINS IRRADIATED IN $\times 310$

$\times 310$

Subassembiy

Pin No.

ZP 7-16

7-12

7-40

7-01

7-18

5-31

5-32

7-09

7-57

7-49

$7-60$

5-45

5-40

7-38

7-58

7-25

5-44

5-35

5-51

5-42

5-09

7-59

7-62

7-64

5-38

5-34

7-11

7-61

7-28
Position

1

2

3

4

5

6

7

8

9

10

11

12

13

14

15

16

17

18

19

20

21

22

23

24

25

26

27

28

29
Previous

Subassembly

$\times 225$

$\times 225$

$\times 224$

$\times 225$

$\times 225$

$\times 226$

$\times 226$

$\times 225$

$\times 226$

$\times 224$

$\times 226$

$\times 226$

$\times 226$

$X 224 \& X 309$

$\times 226$

$\times 225$

$\times 226$

$\times 226$

$\times 309$

$\times 226$

$\times 224$

$\times 226$

$\times 226$

$\times 226$

$\times 226$

$\times 226$

$\times 225$

$\times 226$

$\times 225$ 
TABLE 5 (Cont'd)

$\times 310$

Subassembly

Pin No.

ZP 7-67

$7-53$

$7-55$

7-65

7-29

$7-54$

7-35

$7-17$
Position

30

31

32

33

34

35

36

37
Previous

Subassembly

$\times 226$

$\times 226$

$\times 226$

$\times 226$

$\times 225$

$\times 226$

$\times 224$

$\times 225$

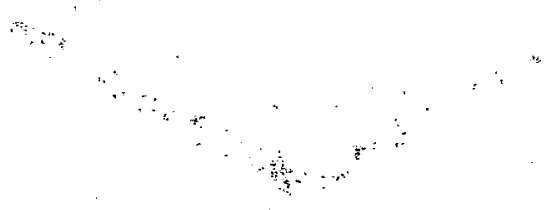




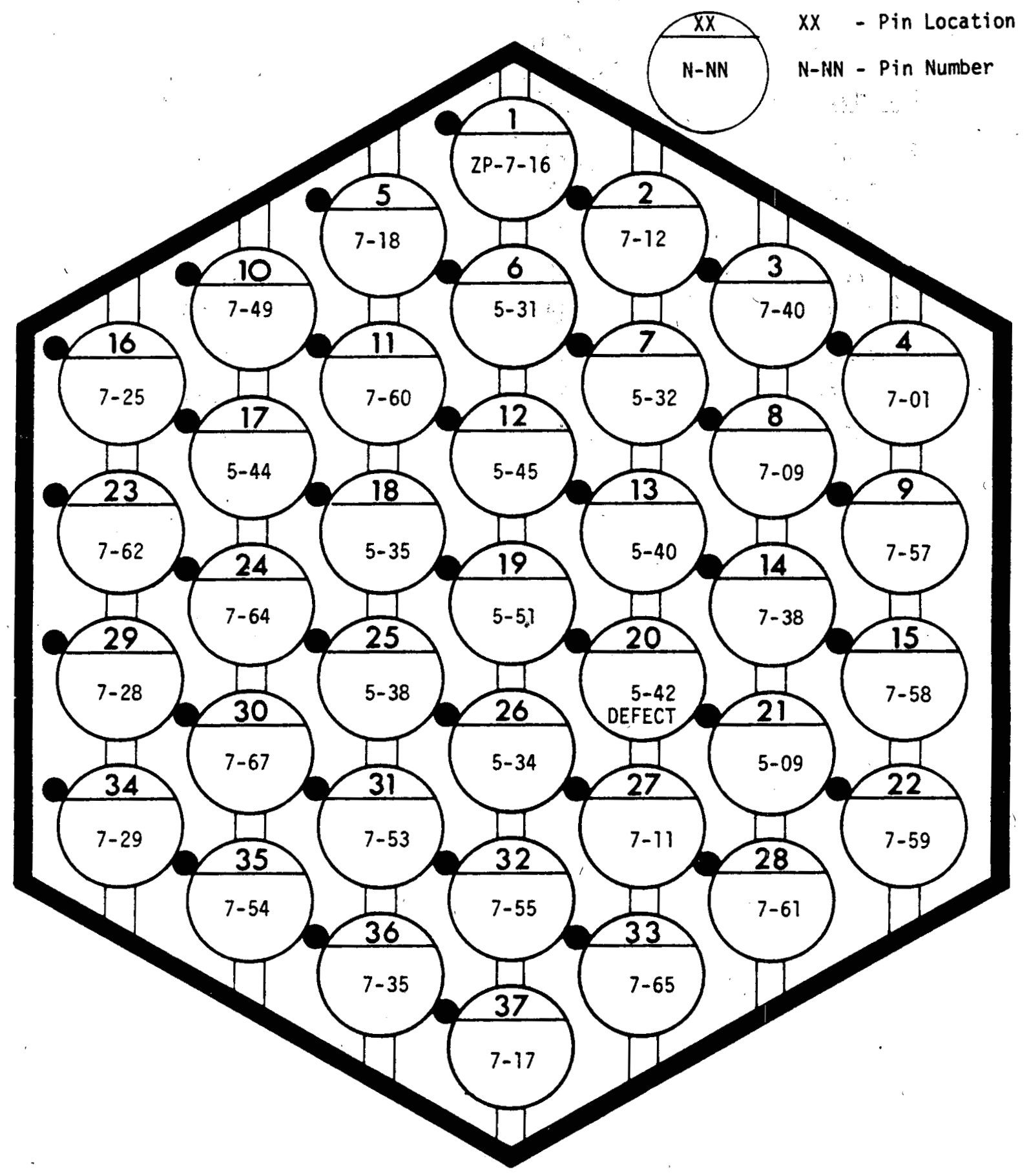

FIGURE 7. Loading Diagram for RBCB-7. "X" Indicates the Defect Orientation. The black circles represent the relative, ideal wire-wrap locations in the subassembly, not necessarily at the defect height. 
No problems were encountered during the loading operation. The hexagonal duct was lowered over the fuel pin bundle with little resistance and welded to the lower spool piece. The subassembly was placed in the HFEF/N storage pit until it was inserted into EBR-II the next day. Sodium ingress probably occurred immediately upon insertion into EBR-II.

The RBCB-7 subassembly was irradiated in position 6E2 of EBR-II during Run 90A. The peak power for the predefected fuel pin (ZP-5-42) was 244 watts $/ \mathrm{cm}$. The subassembly coolant flow rate was $1.42 \mathrm{~kg} / \mathrm{s}$. Fission rates are given in Table 6.

TABLE 6

IRRADIATION INFORMATION

\begin{tabular}{|c|c|c|c|c|}
\hline Subassembly & $\begin{array}{c}\begin{array}{c}\text { Pin } \\
\text { Number }\end{array} \\
\end{array}$ & $\begin{array}{c}\text { Peak Pin } \\
\text { Power }(\mathrm{W} / \mathrm{cm}) \\
\end{array}$ & $\begin{array}{c}\text { Fission Rate } \\
\left(\text { fissions/g-s } \times 10^{-12} \text { ) }\right. \\
2355_{U} 238 \mathrm{U} 239 \mathrm{Pu} 240 \mathrm{Pu}\end{array}$ & $\begin{array}{l}\text { Subassembly } \\
\text { Coolant } \\
\text { Flow Rate } \\
(\mathrm{kg} / \mathrm{s}) \\
\end{array}$ \\
\hline X310 (RBCB-7) & $Z P-5-42$ & 244 & $\begin{array}{llll}7.812 & 0.538 & 9.096 & 3.370\end{array}$ & 1.42 \\
\hline
\end{tabular}

The DN limit for the RBCB-7 test was based on information obtained from the RBCB-6 test. For the RBCB-6 test it was hypothesized that particulate fue 1 might be released through the cladding slit, that the fuel particles might form a coolant channe 1 blockage in the core region ${ }^{(8)}$ and that the release of DN precursors from the particulate fuel would be by a recoil mechanism. An analysis based on these assumptions indicated that a potentially damaging coolant channel blockage would produce a signal of at least 120 counts/s. This increase constituted a basic signal safety margin against coolant channel blockage. Accordingly, the DN 1 imit for the RBCB-6 test was 120 counts/s above the DN signal observed when the reactor first reached full power. A signal above this limit required a manual reactor scram and termination of the test. 
Examination of the data from RBCB-6 suggested that a higher signal limit would be justified for RBCB-7. Thus, the administrative limit for RBCB-7 was set at two times the signal when full power was attained minus the background signal. In no case was the signal to exceed 1300 counts/s. 


\section{RBCB-7 IRRADIATION HISTORY}

The irradiation of RBCB-7 (X310) started at 2331 hours on August 15, 1977 with the rise to power beginning EBR-II Run 90A. The reactor scrammed upon reaching $60 \mathrm{MWt}$ at 0522 on August 16, 1977. The scram was not caused by RBCB-7 but by erroneous subassembly out let thermocouple readings.

The reactor was restarted on 0726 , August 16, 1977 and full power (62.5 MWt) was reached at 1128 . The test was terminated by a reactor scram at 1357 , August 16, 1977 after 2-1/2 hours of full-power operation. Test termination was required because the DN signal spike from $\times 310$ exceeded the administrative manual scram alarm setting of $800 \mathrm{cps}$.

DN signals from Fuel Element Rupture Detection (FERD) channel $1 \mathrm{~B}$ were selected to illustrate the DN behavior during the RBCB tests. DN from the reactor core were monitored on all three of the FERD system channels during the RBCB tests. Channel $I B$ is the only channel that is consistent from test to test because channe $I S A$ and $1 C$ were modified during the course of RBCB testing. The background DN signals of about 50 counts/s were comparable for both RBCB-6 and -7 .

The behavior of the DN signal and reactor power with time are shown in Figure 8. The FERD system alarm setting was established during the initial rise to power. The alarm setting was twice the full power DN signal (425 counts/s) minus the normal background ( 50 counts/s) or 800 count/s. The DN signals were higher during the reactor restart than during the initial startup (Figure 9).

Both RBCB-6 and - -7 exhibited nonlinear DN behavior with respect to reactor or pin power (Figure 9). The DN signals from RBCB-7 were generally higher than those in RBCB-6, especially in the nonlinear region. 

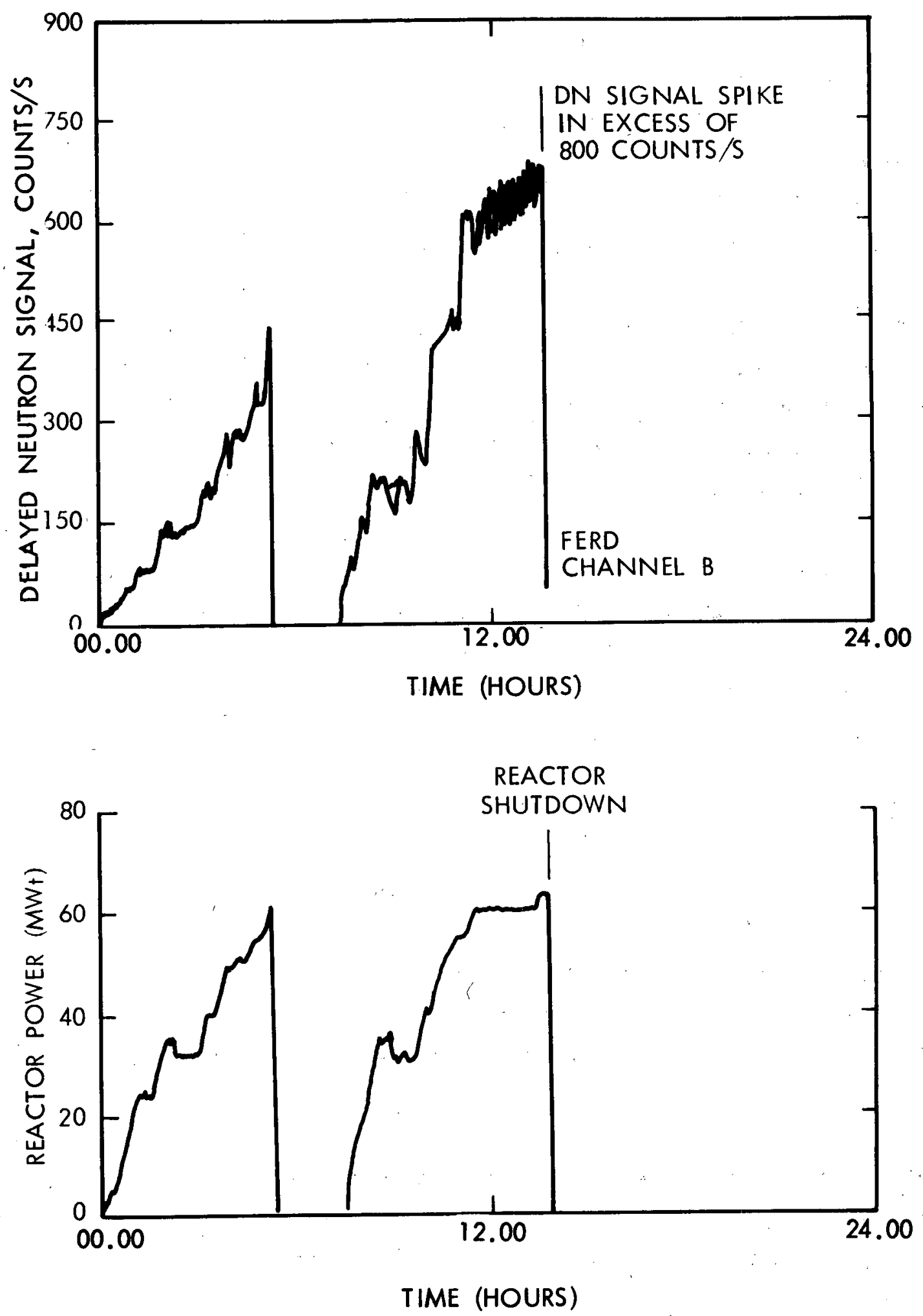

FIGURE 8. Reactor Power and Delayed Neutron Signal Time History During RBCB-7, EBR-II Run 90A. Neg 7909733-4 


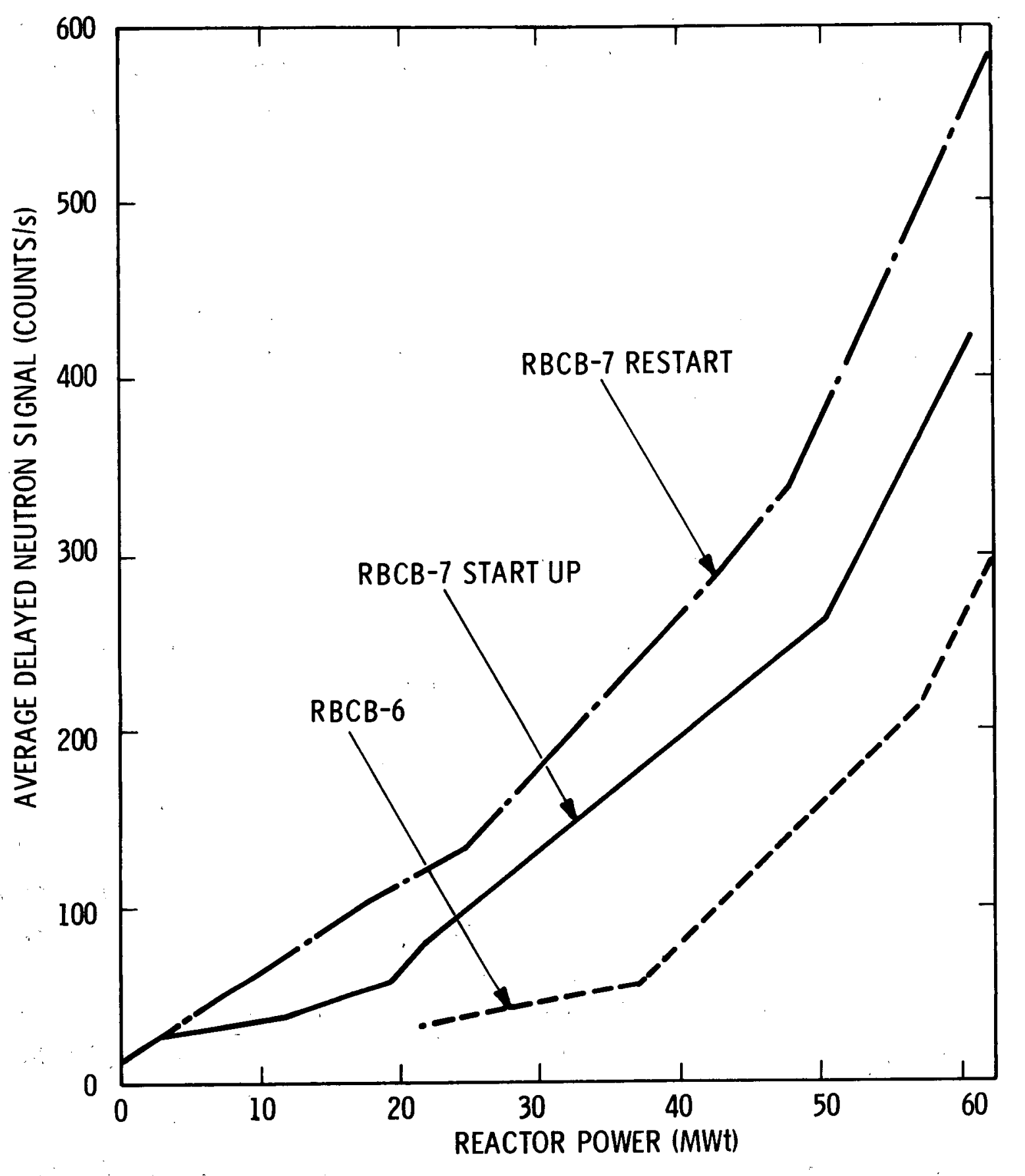

FIGURE 9. Delayed Neutron Signal from RBCB-7 Increased Nonlinearly with Reactor (or Pin) Power. Neg 7909733-1 
During operation at full power, the DN signal continued to increase gradually as shown in Figure 10 . The data points in Figure 10 were obtained by averaging DN data recorded at a rate of two points per second over five-minute intervals.

The on ly previous experience with mixed-oxide fue 1 exposed directly to the EBR-II coolant was the breached fuel pin ZP-8-24 in the RBCB-6 test. ${ }^{(6)}$ The DN signal continued to increase gradually during full power operation with this test also. However, the rate of DN signal increase was less than in RBCB-7 and occurred over a longer period of time.

Fission gas release from $\mathrm{RBCB}-7$ caused a significant increase in the activity of reactor gases with the exception of ${ }^{133} \mathrm{Xe}$. The level of ${ }^{133} \mathrm{Xe}$ is low. because the fuel pins had been out of reactor long enough prior to RBCB irradiation for the existing ${ }^{133} \mathrm{Xe}$ ( 5.25 day half-life) to have decayed away. The RBCB irradiation time was not long enough for a significant amount of new ${ }^{133} \mathrm{Xe}$ to accummulate in the fuel. The behavior of the fission gases was much more erratic than that observed in the RBCB-6 test. Use of the cover gas cleanup system (CGCS) may have contributed to the complicated behavior of the released fission gases during RBCB-7.

The RBCB-7 subassembly was removed from the reactor on August 22, 1977 after six days of cooling in the reactor core basket. The subassembly was raised into the Fuel Unloading Machine (FUM) where hot $\left(400^{\circ} \mathrm{C}\right)$ argon was blown down through the subassembly for one hour to remove sodium. The subassembly was transferred to the Interbuilding Coffin (IBC) for transport to HFEF/N. The transfer occurred without forced cooling and without washing.

Decay heat calculations made by EBR-II personnel indicated that because of the brief irradiation, the transfer could be made in stagnant argon without exceeding a cladding temperature of $427^{\circ} \mathrm{C}\left(800^{\circ} \mathrm{F}\right)$. The blowers in the $I B C$ were not used during the transfer to avoid possible contamination of the IBC. 


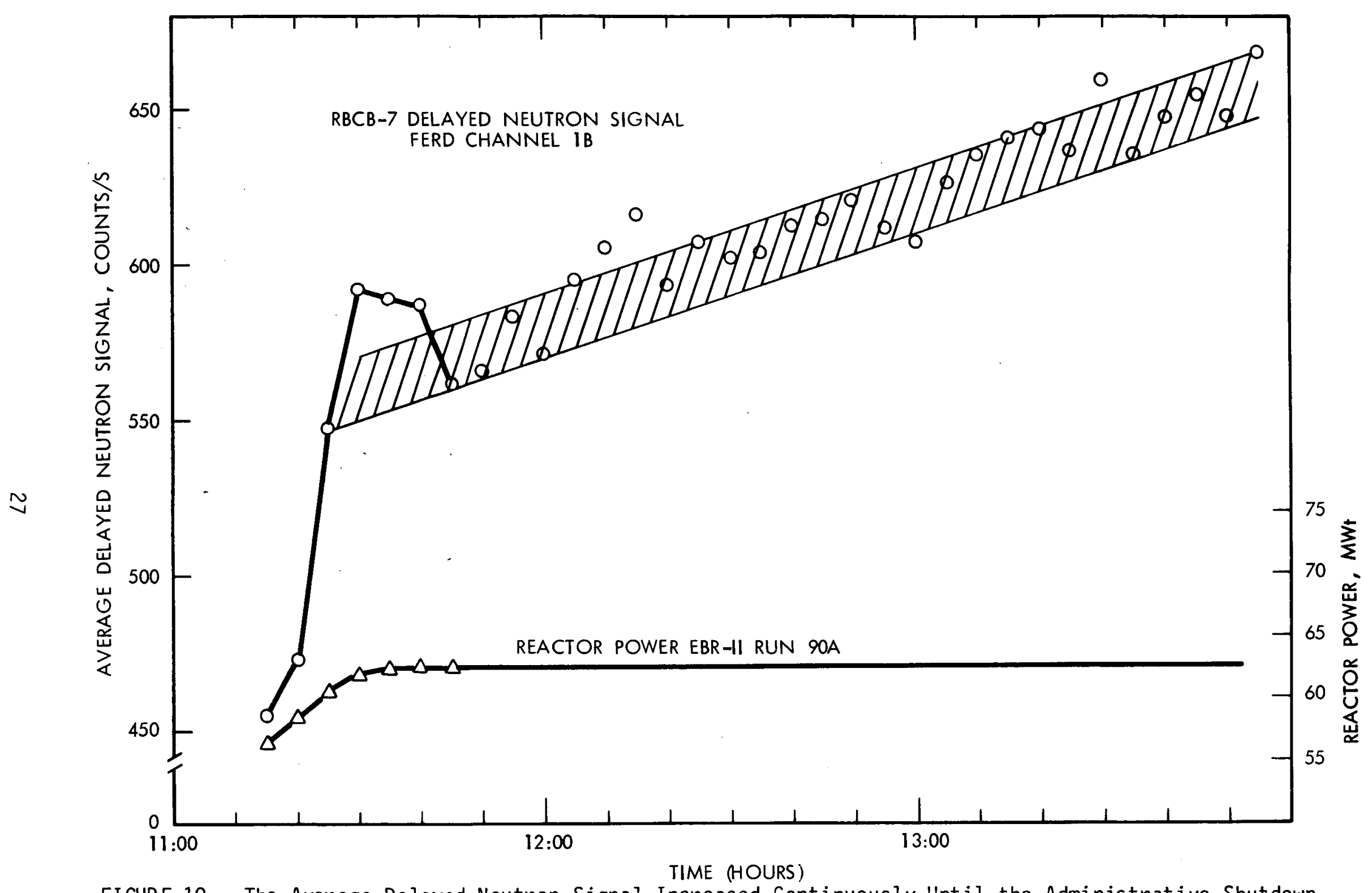

FIGURE 10. The Average Delayed Neutron Signal Increased Continuously Until the Administrative Shutdown Limit was Reached. Neg 7909733-8 


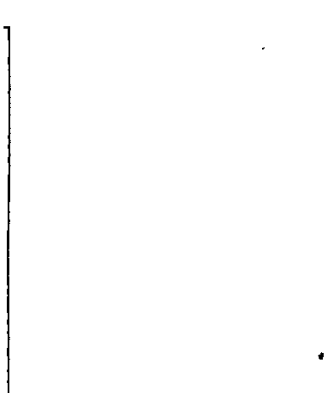




\section{POSTIRRADIATION EXAMINATION}

\section{A. SUBASSEMBLY DISMANTLING}

The potential for dispersal of contamination by flowing argon was investigated by use of the Vertical Assembly-Disassembly (VAD) filter shown in Figure 11. (6) Argon effluent was filtered for four hours and at the conclusion the filter was analyzed for plutonium. The results of this analysis showed there would be no significant spread of plutonium contamination from the subassembly using forced cooling during RBCB subassembly transfers.

Subassembly dismantling begain at the conclusion of the filtering operation. The hex can was cut away from the spool piece. The force required to start hex can removal was 400 pounds. After breaking the hex can loose, the force to continue removal did not exceed 25 pounds.

Nothing unusual was observed on the fuel pin bundle. Some metallic sodium adhered to the cladding under the wire wraps (see Figure 12a) and at the alignment notch. More sodium globules (Figure 12b) were observed in the RBCB-7 (X310) fuel pin bundle than were observed on the RBCB-6 (X309) bundle. The fuel pin had a dark appearance from the bottom up to about one-half inch above the lower end cap weld. The sodium dispersion in this area looked like "powered sugar" (see Figure 12c). Above the dark area the cladding was generally bright and metallic with the exception of some darkening of the breach area.

The subassembly and fuel pins were in good condition with no evidence that pins surrounding the predefected pin were affected by RBCB irradiation.

The upper collector screens from the $X 309$ and $X 310$ subassemblies were examined for deposits of material from the breached $(10,11)$ pins. Even though the subassemblies were irradiated for short periods, the background radiation levels from activated $\mathrm{Mn}, \mathrm{Co}$ and $\mathrm{Ni}$ in the collector were high enough to preclude accurate measurement of the relatively small deposit 


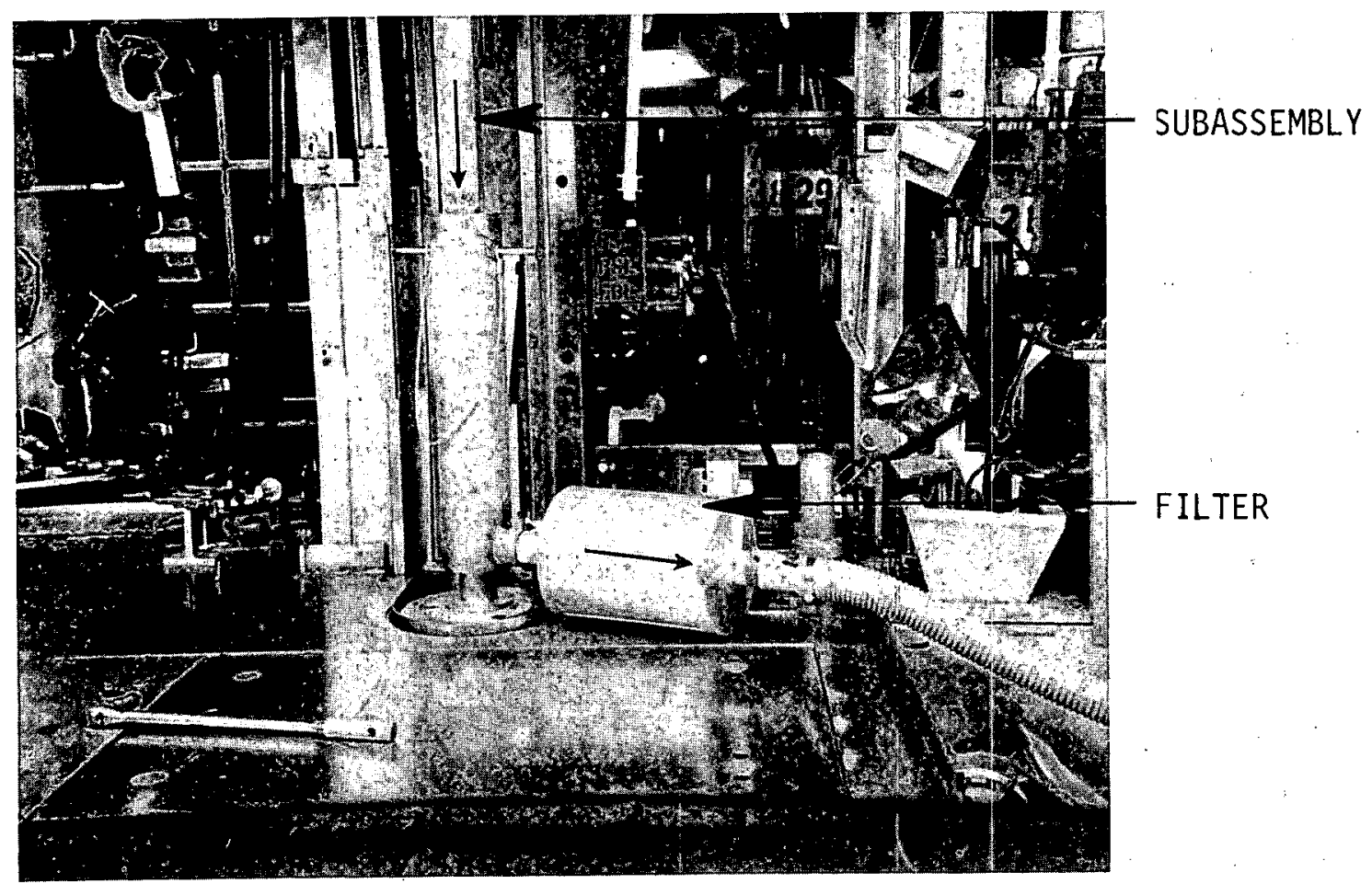

FIGURE 11. VAD Filter Installed to Investigate a Potential Spread of Pu Contamination from an RBCB Subassembly During Forced Cooling. Neg 103-112154 


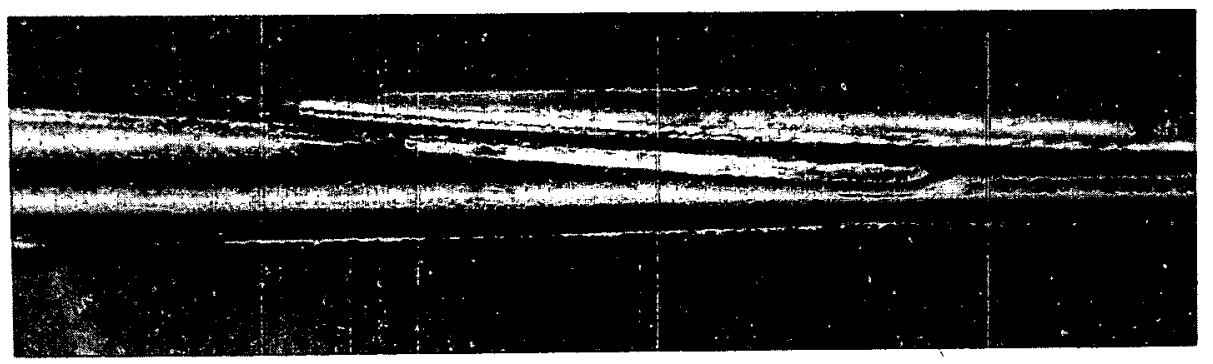

a) Under the Wire Wrap

b) Globules

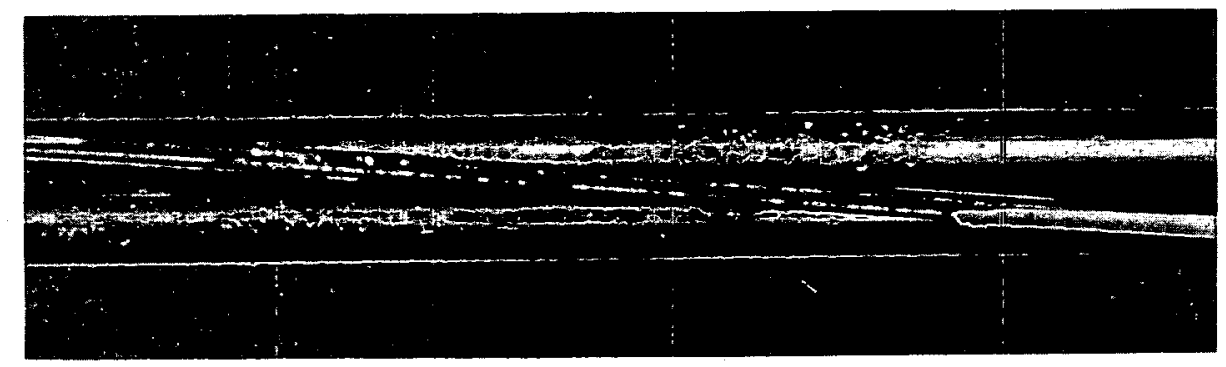

c) 'Powered Sugar'

FIGURE 12. Appearance of Sodium Remaining on the RBCB-7 Breached Pin (ZP-5-42). Neg 7909733-19 
activities without separating them from the substrate. Indications were that some fission products and some fuel were deposited on the collector, mostly toward the top end. RBCB-7 operated for the shortest time, had the 1 argest defect size and had the largest deposits.

After disassembly, smears were taken from several locations to determine whether plutonium contamination had occurred during transfer and handing of the $x 310$ subassembly. Smears taken from the subassembly exterior and the lower spool piece indicated no plutonium contamination. Smears taken from the VAD machine ranged from $300 \mathrm{dpm}$ to $2250 \mathrm{dpm}$ of alpha. Equipment with a smear reading of $6000 \mathrm{dpm}$ of alpha is considered contaminated in HFEF/N. Relatively high readings were recorded from fuel pin cladding smears taken near the breach in ZP-5-42 (Table 7). The absolute levels for alpha (fuel) contamination, beta-gamma and gamma (fission product) contamination have little significance in themselves since the areas of the smears were not closely controlled.

\section{B. VISUAL EXAMINATION}

Visual examination of the predefected pin showed slit extensions at each end of the slit. The final defect appearance is shown in Figure 13. The original $58-\mathrm{mm}(2.3-\mathrm{in.})-1$ ong slit extended $8 \mathrm{~mm}$ (0.31 in.) toward the top of the fue 1 pin and $32 \mathrm{~mm}(1.25 \mathrm{in.})^{2}$ toward the bottom. The upward slit extension extended about $5.5 \mathrm{~mm}(0.21 \mathrm{in.})$ over the $\mathrm{UO}_{2}$ insulator region. The final dimensions of the defect are shown in Table 8 along with the initial dimensions. The total area of the defect increased from $0.35 \mathrm{~cm}^{2}$ to $0.71 \mathrm{~cm}^{2}$, an increase of $103 \%$.

What appeared to be sodium-fuel reaction product was still below the surface of the cladding and there was no evidence of fuel release. The extension of the machined slit was the only visible effect of the RBCB irradiation. Careful examination of the neighboring pins, especially the one facing the slit, showed no effect of the RBCB irradiation. 
TABLE 7

ZP-5-42 IN-CELL SMEAR SURVEY DATA

\begin{tabular}{|c|c|c|c|}
\hline Location & $\begin{array}{c}\text { Beta/Gamma } \\
\text { (mr/h o } 1.75 \text { in.) }\end{array}$ & $\begin{array}{c}\text { Gamma } \\
(\mathrm{mr} / \mathrm{h} \stackrel{0}{0} 1.75 \text { in. }) \\
\end{array}$ & $\begin{array}{l}\text { Alpha } \\
\text { (dpm) }\end{array}$ \\
\hline $\begin{array}{l}\text { Above Breach } \\
\text { Bel ow Breach }\end{array}$ & $\begin{array}{l}360 \\
100\end{array}$ & $\begin{array}{l}16 \\
12\end{array}$ & $\begin{array}{l}75,000 \\
77,350\end{array}$ \\
\hline
\end{tabular}

TABLE 8

RBCB -7 CLADDING DEFECT DIMENSIONS

\begin{tabular}{|c|c|c|c|}
\hline & $\begin{array}{l}\text { Width } \\
\text { (mm) }\end{array}$ & $\begin{array}{l}\text { Length } \\
(\mathrm{cm})\end{array}$ & $\begin{array}{l}\text { Area } \\
\left(\mathrm{cm}^{2}\right)\end{array}$ \\
\hline Pre-RBCB Irradiation & 0.76 & 5.84 & 0.35 \\
\hline Post-RBCB Irradiation & 1.40 & 10.06 & 0.71 \\
\hline
\end{tabular}


(a)

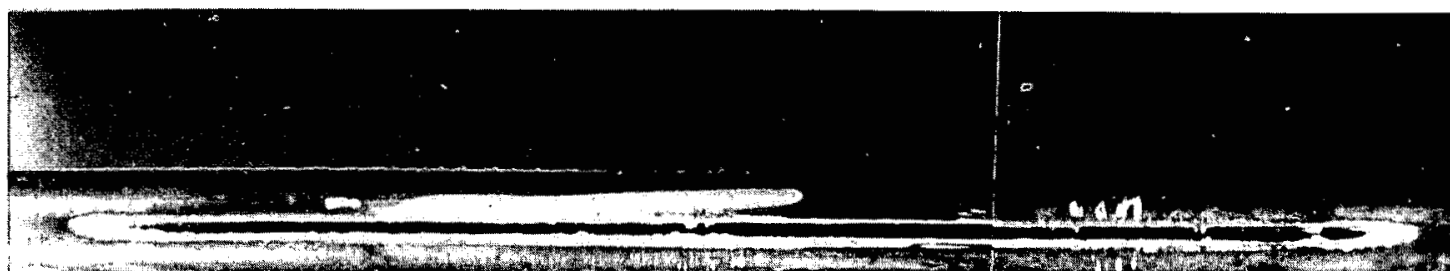

(b)
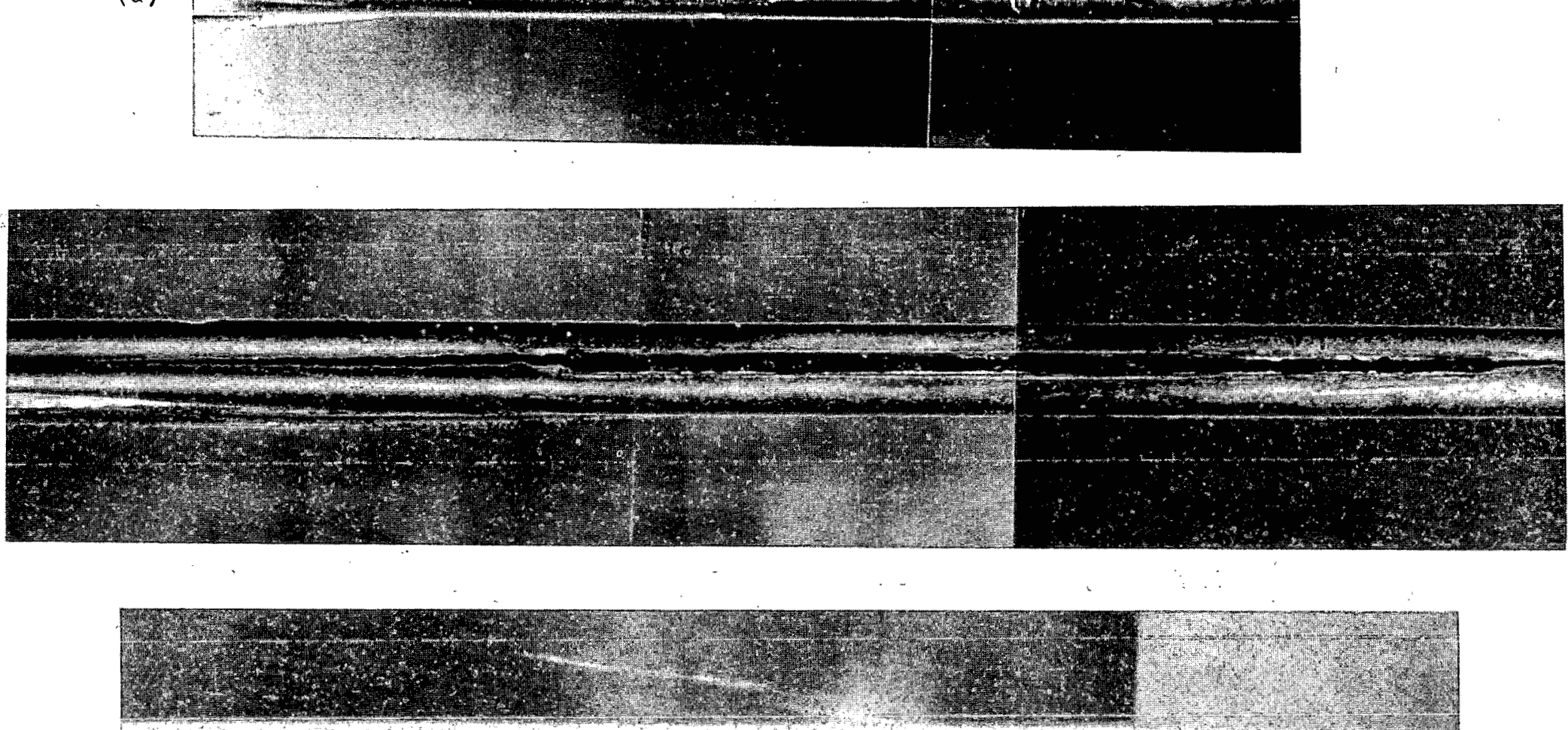

(c)

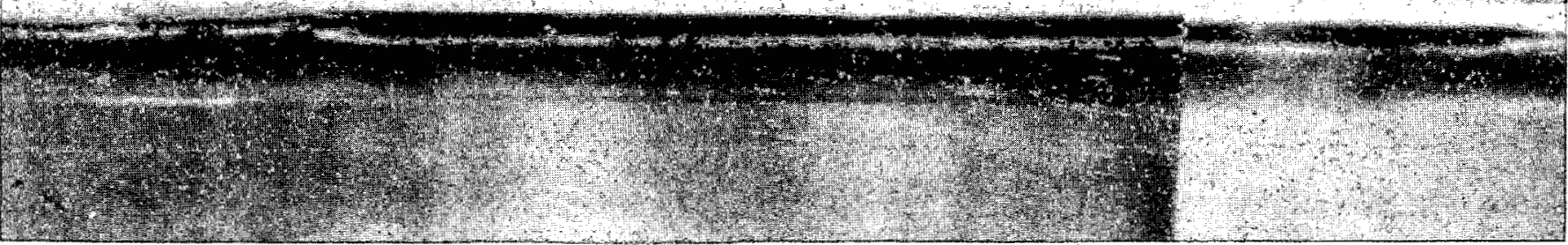

FIGURE 13. The Breach Appearance of RBCB-7 (ZP-5-42): a) As-Fabricated and Post-RBCB Irradiation, b) at HFEF/N and C) at HEDL (As-Received) After Filling the Breach with Resin and Shipping from HFEF/N. Neg 7909733-15 


\section{GAMMA SCAN}

The post-RBCB gross gamma scan (Figure 14) was relatively flat from the bottom of the fue 1 (BOF) to about $21.6 \mathrm{~cm}(8-1 / 2 \mathrm{in}$.$) above the BOF at which$ point the scan began to decrease until a one-third decrease in intensity was achieved at the top of the fuel column. This same type of profile also occurred in some of the other fue 1 pins from $\times 224, x 225$ and $\times 226$.

A review of pre- and post-RBCB isotopic gamma scans yielded the following observations:

1) Even though cladding material was removed during machining of the slit, a local loss of cladding material was not evident from a comparison of either the $54 \mathrm{Mn}$ scans or the 58 Co scans.

2) There was no indication of a change in the distribution of $95 \mathrm{Nb}$ or $95 \mathrm{Zr}$, which are dispersed in the fue 1 matrix and are relatively immobile. For this reason, it is unlikely that there was any significant fue 1 loss during RBCB irradiation.

3) The ${ }^{137} \mathrm{Cs}$ in the upper two-thirds of the fuel column was significantly reduced during the RBCB irradiation (Figure 15). The decrease in CS activity in the top two-thirds of the pin is attributed to the release of the more mobile cesium into the sodium coolant.

\section{FISSILE ASSAY}

A fissile assay technique was developed by EG\&G at the Advanced Reactor Measurement Facility (ARMF) ${ }^{(9)}$ to determine the fue 1 losses from RBCB fue 1 pins. Reactivity profiles determined for the predefected, irradiated fue 1 pin (ZP-5-42) after defecting and again äfter subsequent irradiation are shown in Figure 16 .

The scatter in the data made it dificult to discern any effects of the RBCB irradiation. A statistical analys is was performed to determine whether or not the pre- and postirradiation profiles were statistically the same. Using Student's " $t$ " test, the hypothes is that the pre- and potirradiation 
DISTANCE FROM TOP OF PIN $(\mathrm{cm})$

$\tilde{\sigma}$

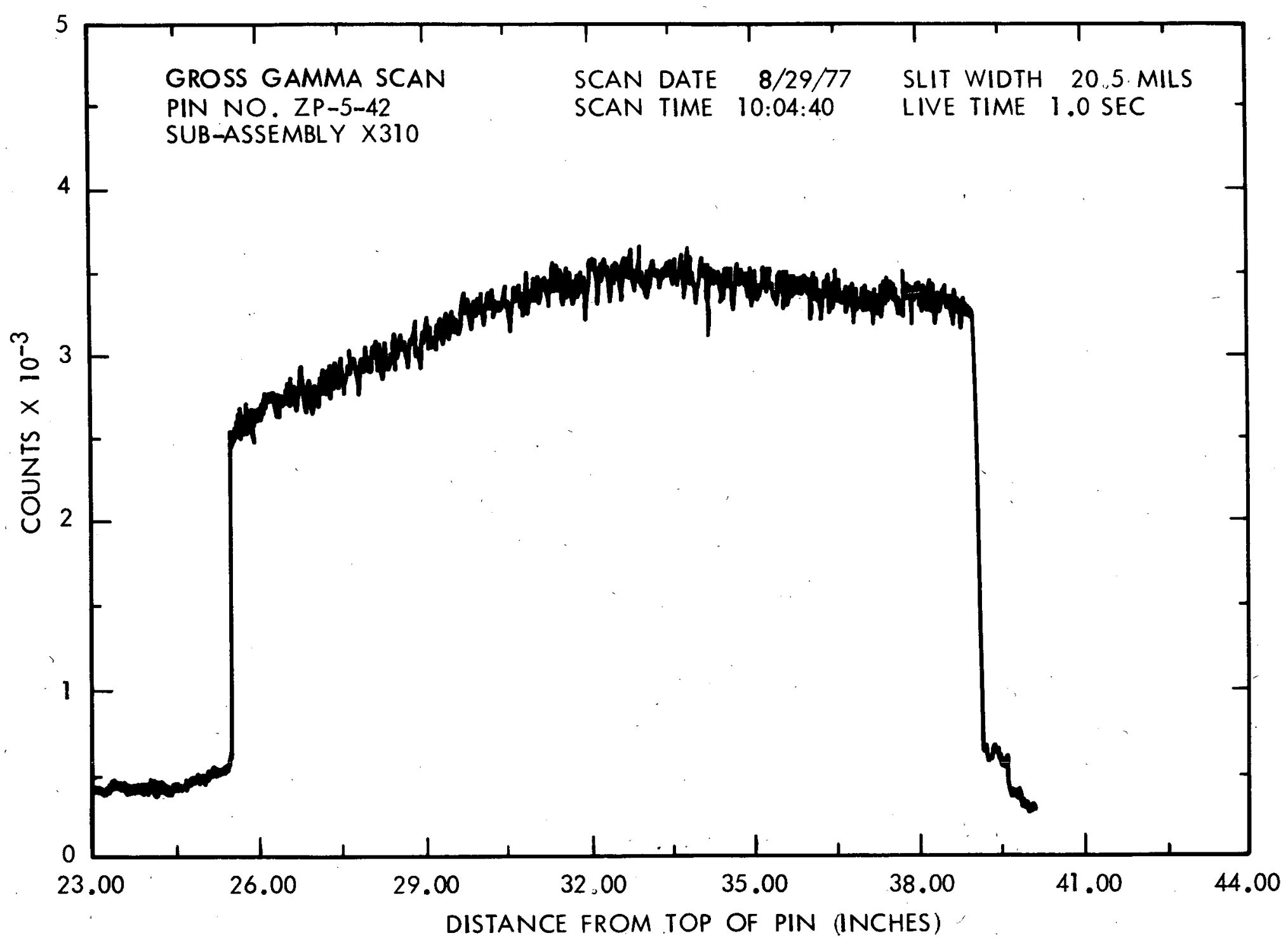

FIGURE 14. Gross Gamma Scan for ZP-5-42 after RBCB Irradiation. Neg 7909733-3 
Z DISTANCE FROM TOP OF ELEMENT $(\mathrm{cm})$

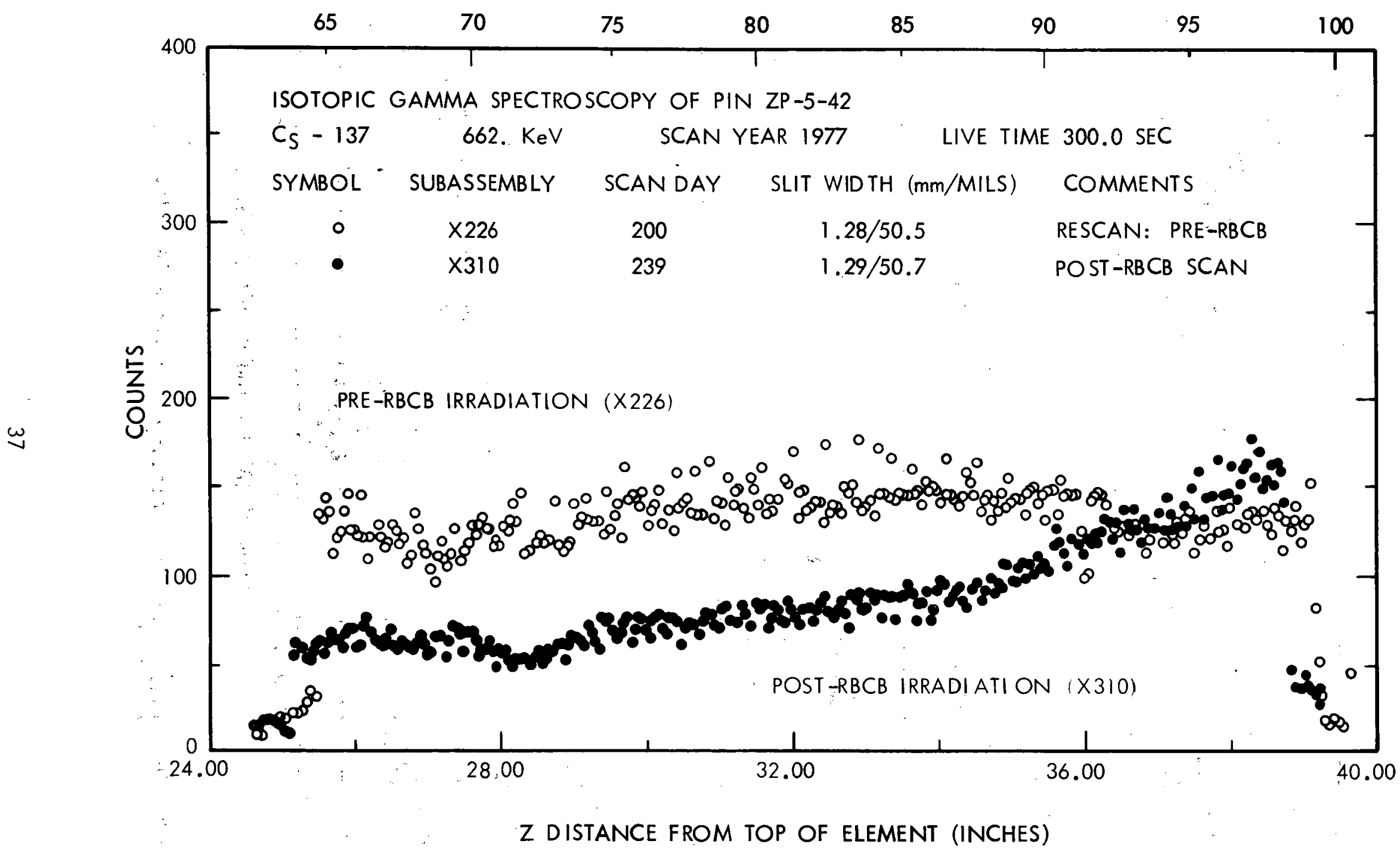

FIGURE 15. Cesium Gamma Scan for ZP-5-42 Before and After RBCB Irradiation. Neg 7909-733-2 


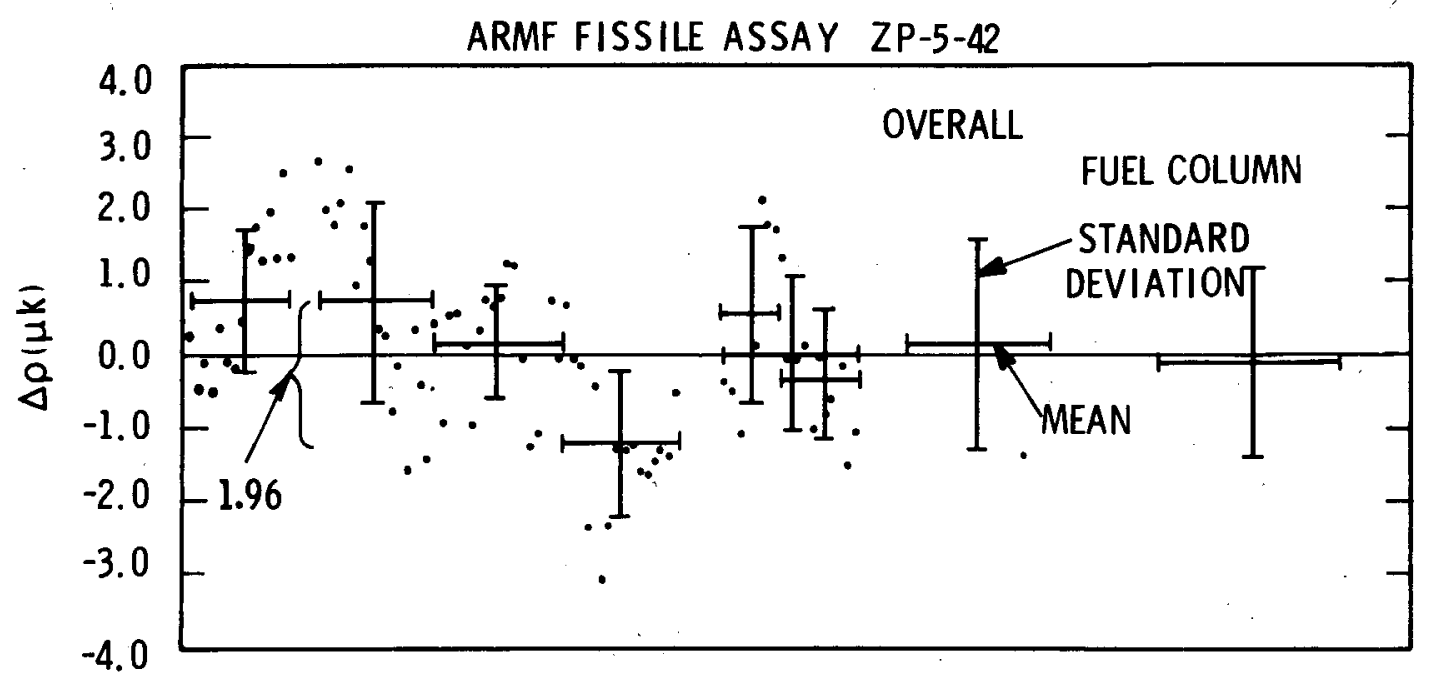

A) DIFFERENCE BETWEEN PRE- AND POST - IRRADIATION REACTIVITY DATA

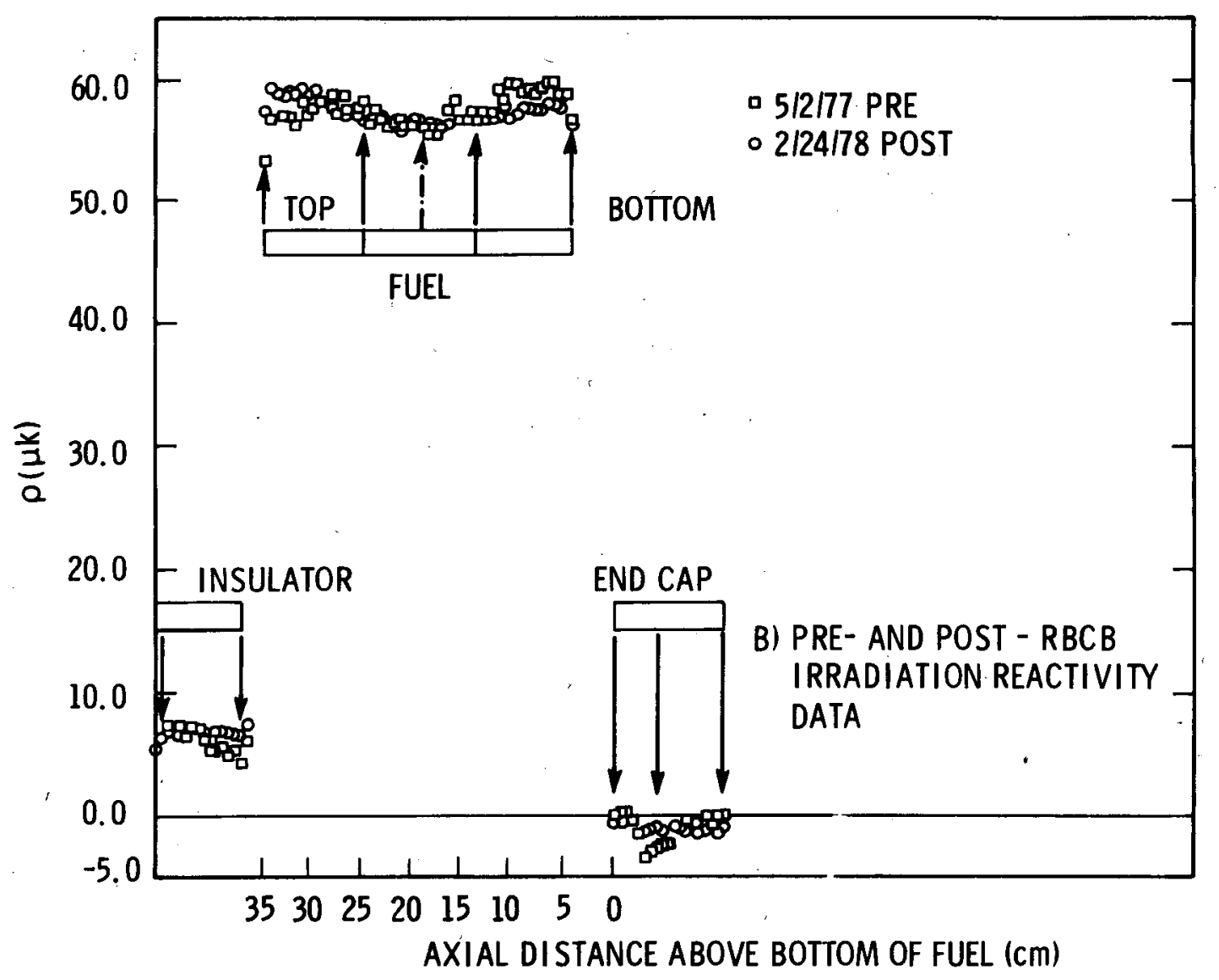

FIGURE 16. Fissile Assay Reactivity Data for RBCB-7 (ZP-5-42). Neg 7911487-2 
means were the same could not be rejected. This implied that there was no measurable change in fuel content over the length of the fuel column during RBCB irradiation.

An evaluation of these data and data from other irradiated fue 1 pins suggests that fuel column end effects, fuel composition, burnup and presence of fission products may affect the reactivity measurements. If so, these factors may limit the sensitivity of the technique. Analysis of reactivity data from several fuel pins is being conducted by EG\&G to resolve the effect of other variables on the measured reactivity.

\section{E. FUEL PIN SWELLING}

The pre- and post-RBCB irradiation diameters for ZP-5-42 are shown in Figure 17. The average maximum diameter increase of $4.7 \%$ occurs over the as-machined slit length and is due to the RBCB irradiation. A prediction of about $4 \%$ diametral swelling was made assuming complete reaction of all available oxygen in the fuel over the full length of the fuel column to form an $\mathrm{Na}_{3}(\mathrm{U}, \mathrm{Pu}) \mathrm{O}_{4}$ layer of uniform thickness and $100 \%$ theoretical density $(5.57 \mathrm{~g} / \mathrm{cc})$ around the fuel periphery.

The pre-RBCB diameter prior to matching the slit was about $5.855 \mathrm{~mm}$ or $0.2 \%$ greater than the as-fabricated diameter. The neutron-induced cladding swelling (as determined from post-RBCB irradiation cladding density measurements) was less than $0.01 \%\left(\frac{\Delta V}{3 V} \times 100\right)$. Machining the slit in the cladding may have allowed relaxation to occur which would affect the final pin diameter. No attempt was made to measure the pin diameter after the slit was machined. However, the effects of relaxation on pin diameter are expected to be sma11. The net increase in pin diameter during RBCB irradiation is attributed to the effects of the sodium-fuel reaction.

The diameter change at the ends of the slit extension provide an indication of the strain required to cause crack extension. An estimate of the cladding strain for crack extension is $0.7 \%$. 
AXIAL DISTANCE $(\mathrm{mm})$ ABOVE BOTTOM OF FUEL

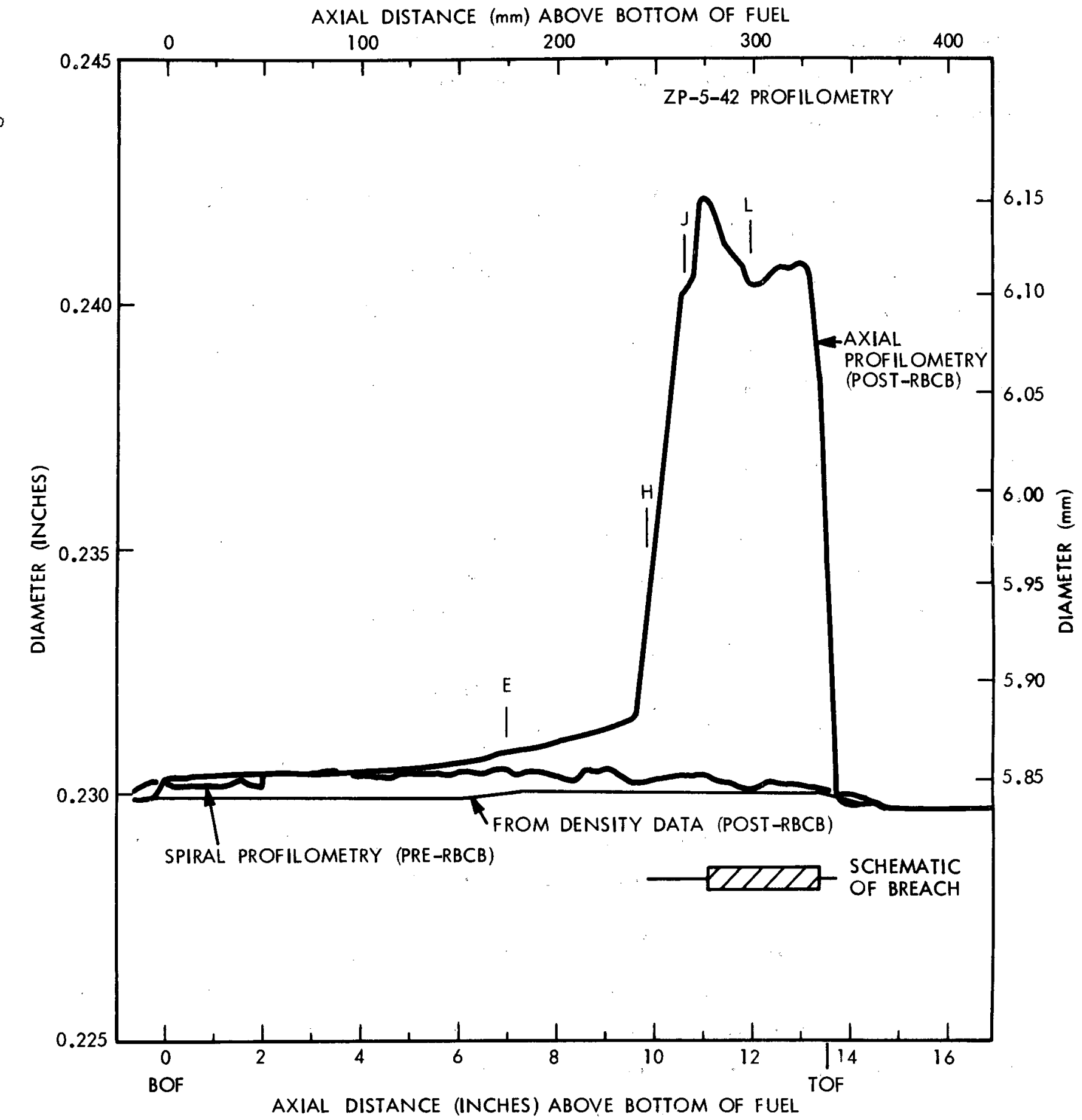

FIGURE 17. Diameter of RBCB-7 Fuel Pin 2P-5-42 Before and After RBCB Irradiation. Neg 7909733-5 


\section{F. NEUTRON RADIOGRAPHY}

Neutron radiography was conducted at EBR-II to monitor structural changes in the fuel and insulator pellets. The 2P-5-42 pin was radiographed after irradiation in X226 and showed normal, structurally sound fuel and insulator pellets. After RBCB irradiation in $X 310$, radiography from $Z \mathrm{P}-5-42$ showed that, except for the breach area, the pin condition was structurally unchanged (Figure 18). The fuel column length was nominally the same $(35.53+0.025 \mathrm{~cm})$. Film density changes in the fueled area were limited to the immediate area of $c l$ adding breach. The area of density change was much less extensive than in the RBCB-6 breached pin (ZP-8-24), which showed density changes over almost half of the pin-image width.

\section{G. FUEL PIN SHIPMENT}

The defected pin was shipped from HFEF/N to HEDL in a closed tube that was designed to prevent the spread of alpha contamination and to maintain an inert environment. The defect itse lf was sealed at HFEF/N by filling it with epoxy resin. The fuel pin was placed in the sealed tube and prepared for shipment to HEDL. The pin appeared to be unaltered when it was removed from the tube at HEDL (Figure 13c). The resin filling the breach was intact. Some white residue (probably oxidized sodium) had collected around the lower end cap weld.

\section{H. FUEL PIN DESTRUCTIVE EXAMINATION}

The purpose of the ceramographic investigation of ZP-5-42 was to gather information that characterized the extent of sodium ingress and the extent of sodium-fuel reaction in a second RBCB fuel pin. Four transverse ceramography sections and four transverse cladd-ing density samples were obtained from the fuel pin. The location of the sections is shown in Figure 19. The four ceramographic sections were obtained from positions along the upper half of the fuel column. The ends of the fuel column and 


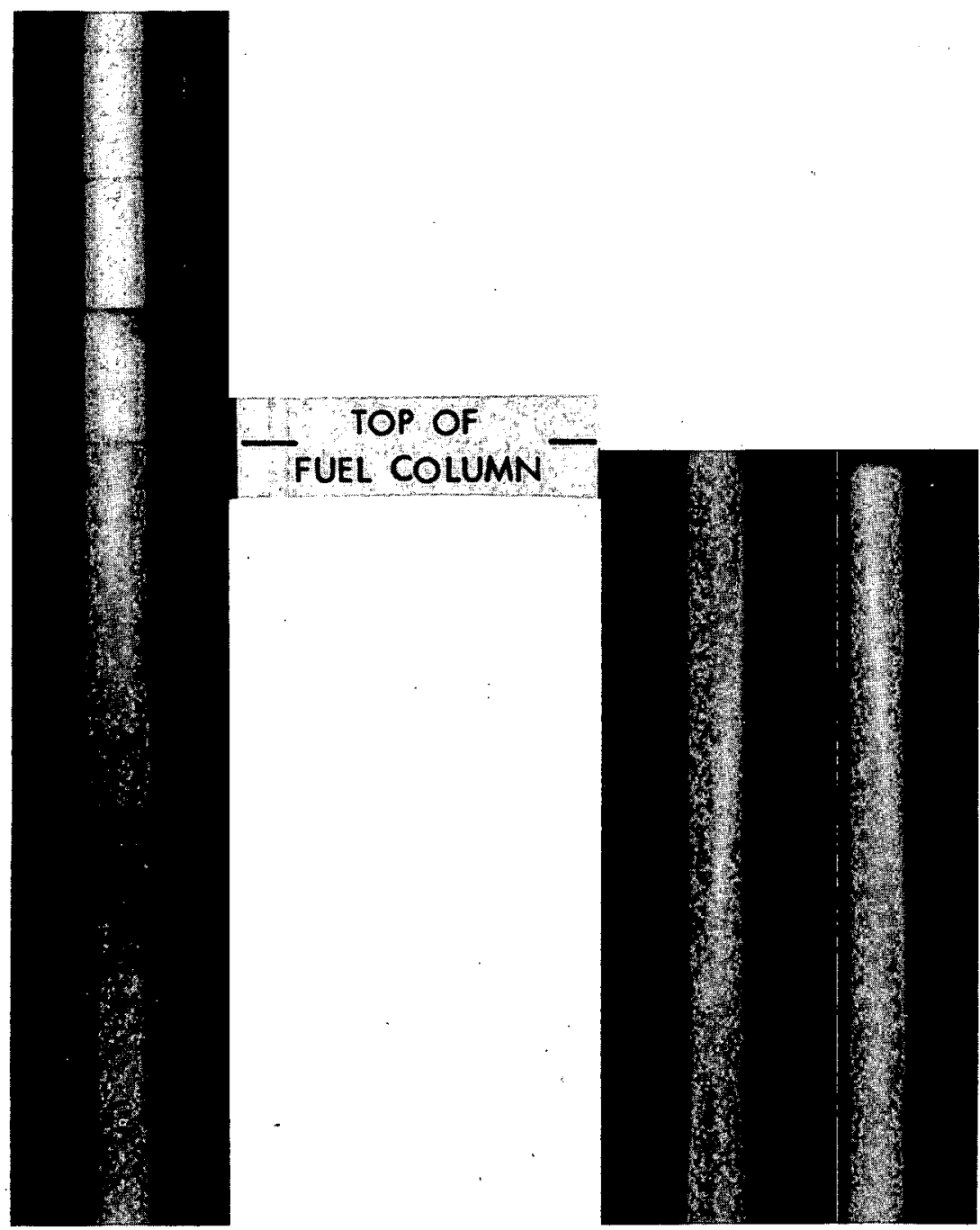

(A)

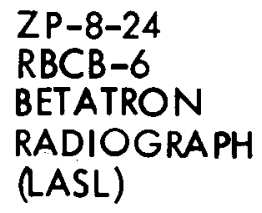

(B)

$\begin{array}{ll}\text { ZP-5-42 } & \text { ZP-5-34 } \\ \text { RBCB-7 } & \text { UNFAILED } \\ \text { NEUTRON } & \text { FUEL PIN } \\ \text { RADIOGRAPH } & \text { NEUTRON } \\ \text { (HFEF) } & \text { RADIOGRAPH } \\ & \text { (HFEF) }\end{array}$

FIGURE 18. Radiography of Two Predefected Fuel Pins After RBCB Operation: a) Betatron Radiograph Showing the Breached Area of RBCB-6 (ZP-8-24), b) Neutron Radiograph Showing the Breach Area of RBCB-7 (ZP-5-42) and C) Neutron Radiograph Showing the Unfailed Fue 1 Pin (ZP-5-34). Neg 7909-094.1 


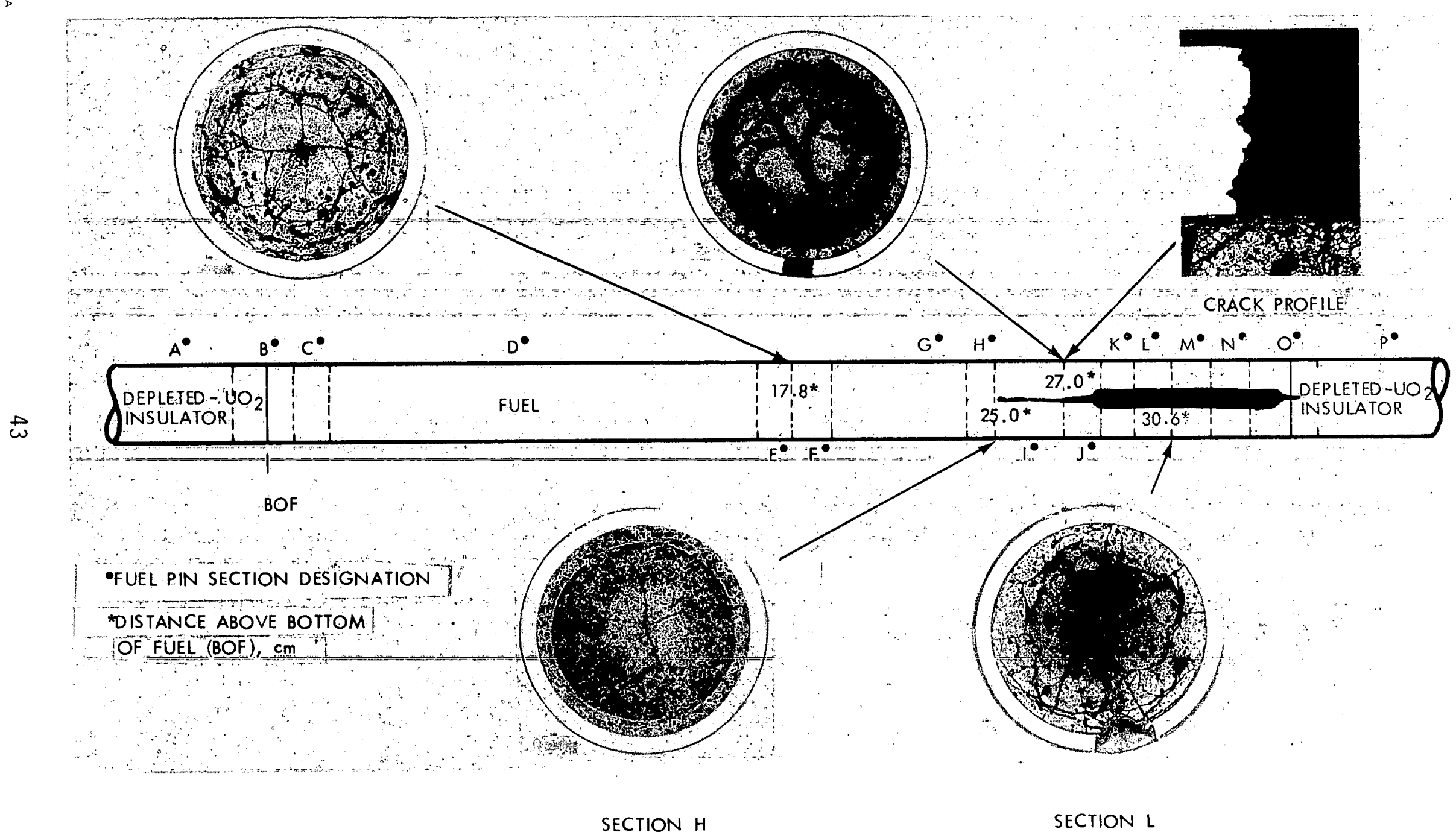

FIGURE 19. A Summary of the Photomicrography for ZP-5-42. Neg 7909733-14 
adjacent $\mathrm{UO}_{2}$ insulator pellets were not examined. Quantitative measurements of the volume fraction of sodium-fuel reaction product were not made because of the artifacts present in the ceramographic sections. Results from the RBCB-6 examination and from the RBCB-7 radiography indicated that little meaningful new information regarding sodium ingress and sodium-fue 1 reaction would be obtained by examining sections of the top and bottom fuel-insulator pellet interface. Therefore, limited time and resources available for hot cell examinations were used to examine the four transverse ceramography samples.

\section{Fuel Pin Sectioning}

Fuel pin sectioning occurred at HEDL in a controlled atmosphere (nitrogen) hot-cell. Sectioning began at the bottom of the pin. Transverse sections of the fuel pellets in the bottom half of the pin exhibited only one or two

major diametral cracks and no indication of sodium ingress. A section from the middle of the fuel column had a small sodium spot. More general pellet cracking and sodium ingress into the outer portion of the fuel occurred at $24 \mathrm{~cm}$ (9.5 in.) above the BOF column and higher. The sodium ingress in Section $J$ differed from that in other sections from the upper third of the fue 1 column in that the sodium ingress was primarily along the major fue 1 crack across the center of the pellet rather than around an outer ring of fue 1. A very small amount of fuel loss was apparent adjacent to the machined slit in Section L. Smearing of sodium-permeated fuel was first observed in the section just above the middle of the machined slit.

\section{Ceramography}

The fuel microstructure in the middle of the machined slit, Section $L$, (Figures 20 and 21), had extensive fallout and preparation artifacts. This section was atypical of the other sections examined. Section $L$ is discussed but not included as a representative fuel section for steady-state RBCB operation. The three other transverse sections (Figures 22 thru 27) showed 


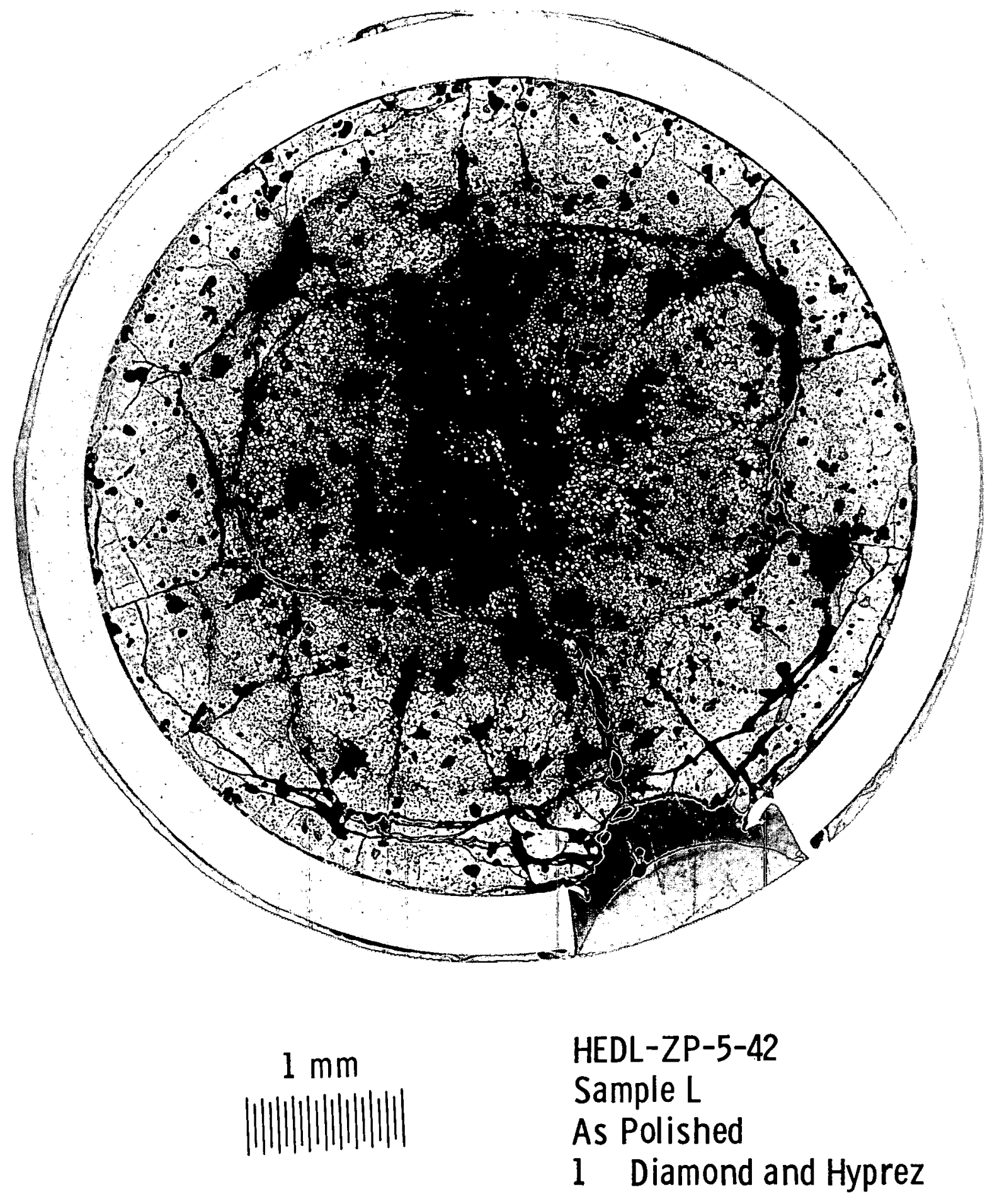

FIGURE 20. Microstructure of HEDL-ZP-5-42 Sample L. Neg 7909733-10 


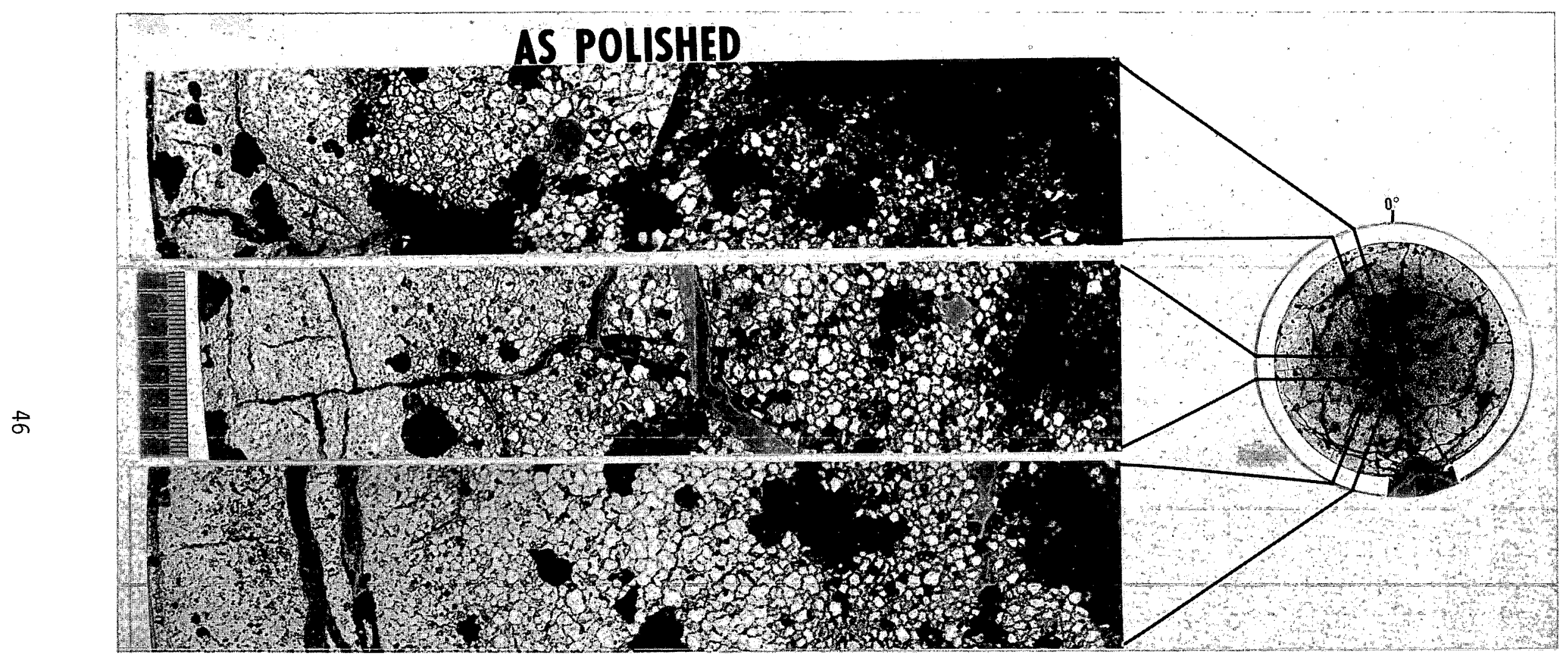

$7907195-3$

HEDL-ZP-5-42

Sample-L

FIGURE 21. Microstructure of HEDL-ZP-5-42 Sample L - Radial Strips. 

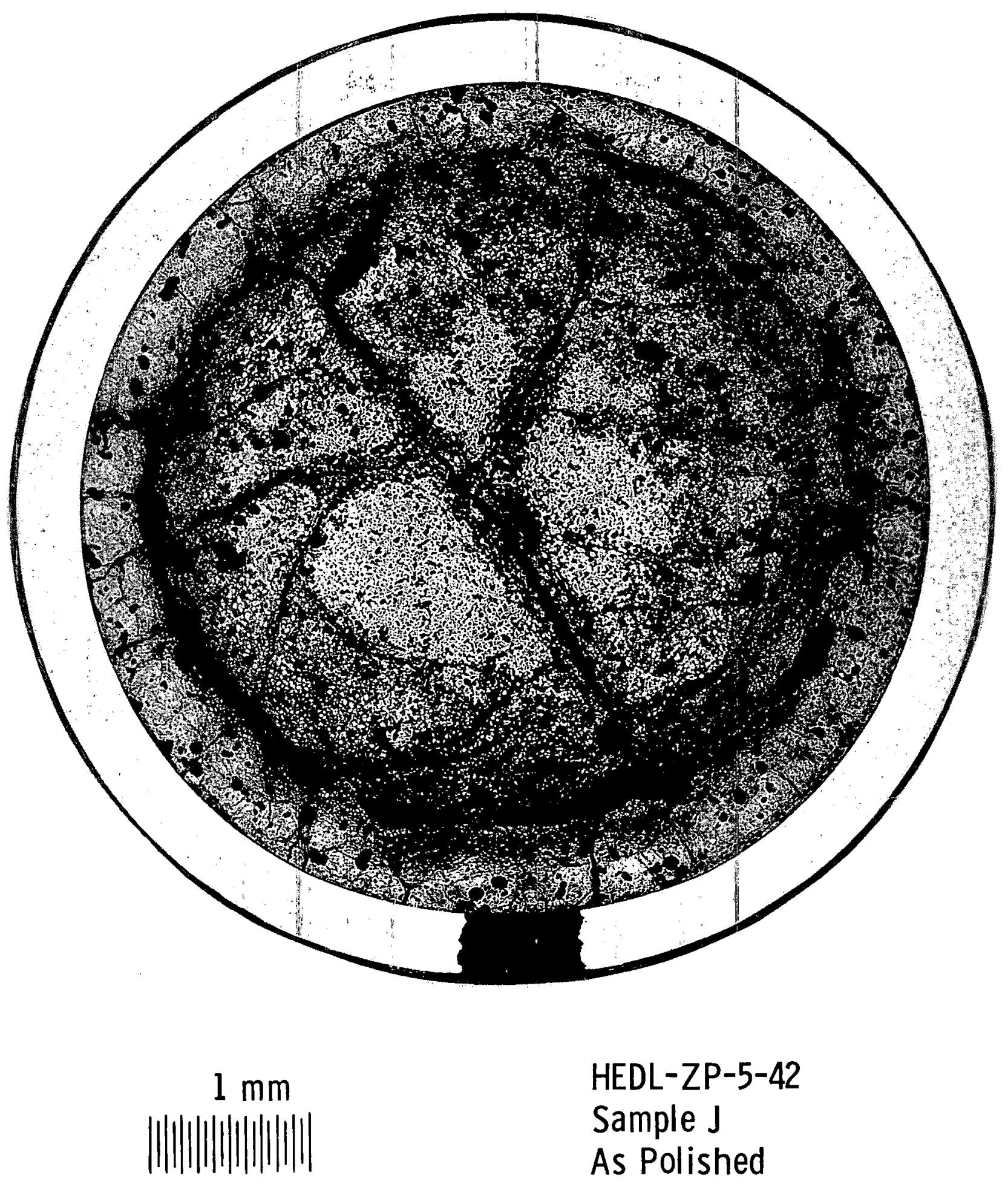

HEDL-ZP-5-42

Sample J

As Polished

1 Diamond and Hypre;

7810326

FIGURE 22. Microstructure of HEDL-ZP-5-42 Sample J. Neg 7909733-12 

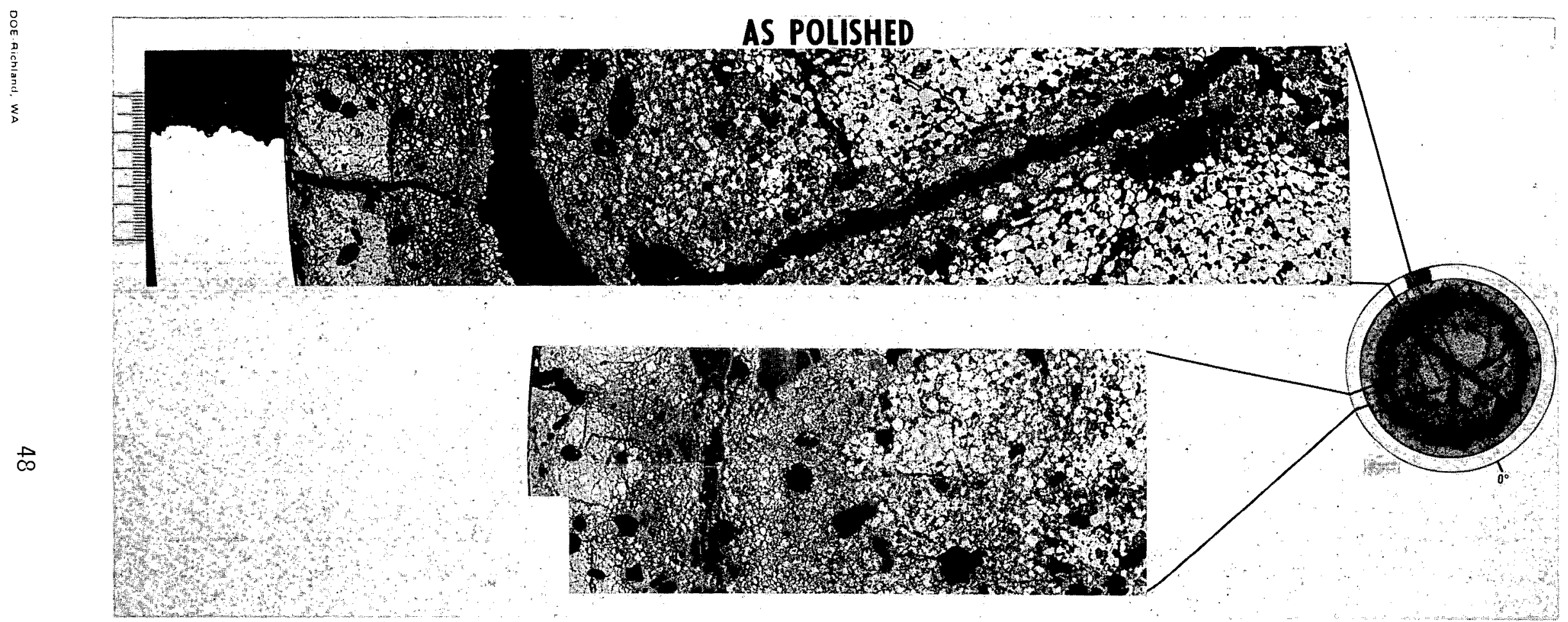

$7907195-4$

HEDL-ZP-5-42

Sample J

FIGURE 23. Microstructure of HEDL-ZP-5-42 Sample J - Radial Strips. 

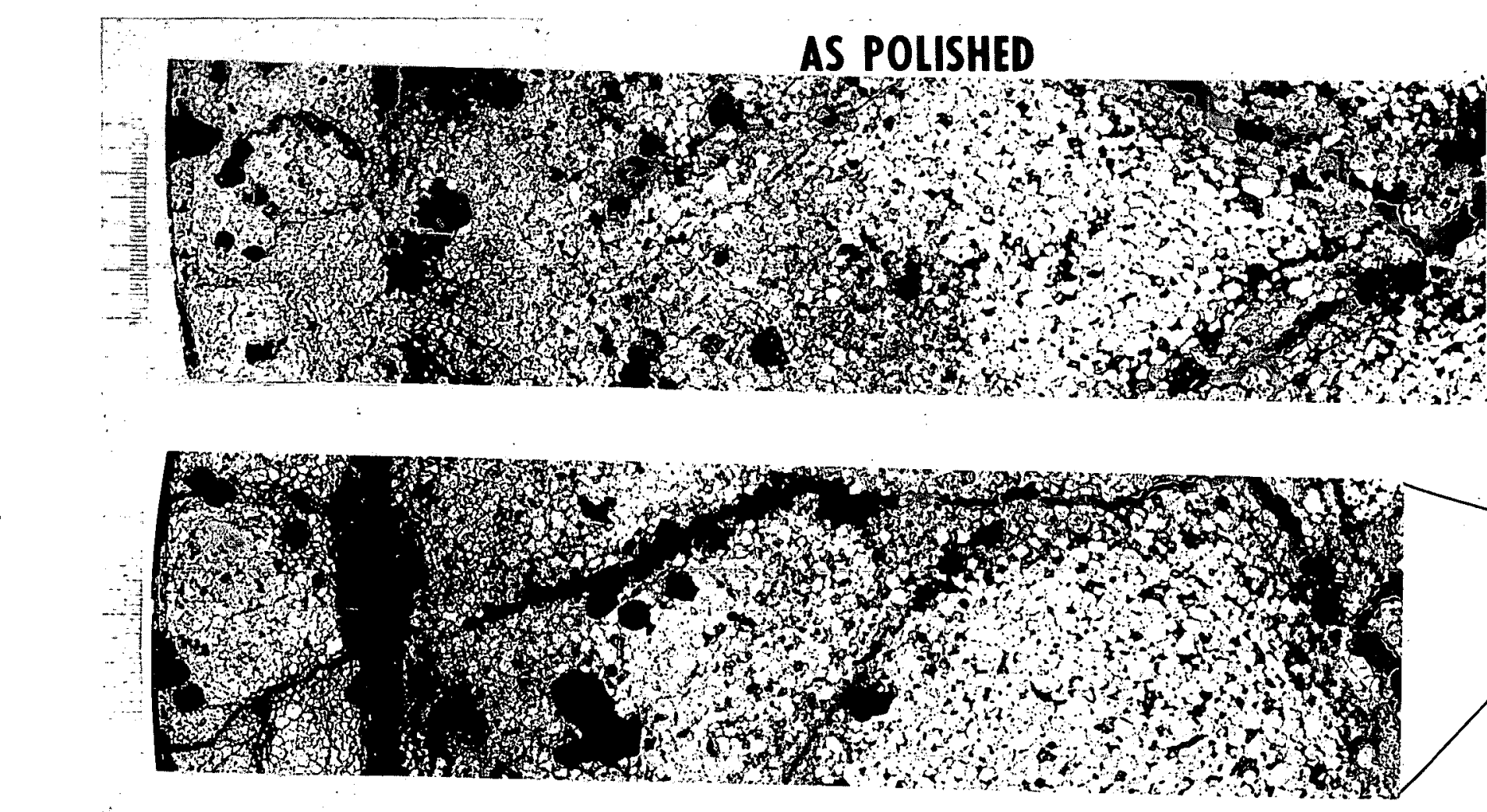

7907195-5

HEDL-ZP-5-42

Sample J

FIGURE 24. Microstructure of HEDL-ZP-5-42 Sample J - Radial Strips. 


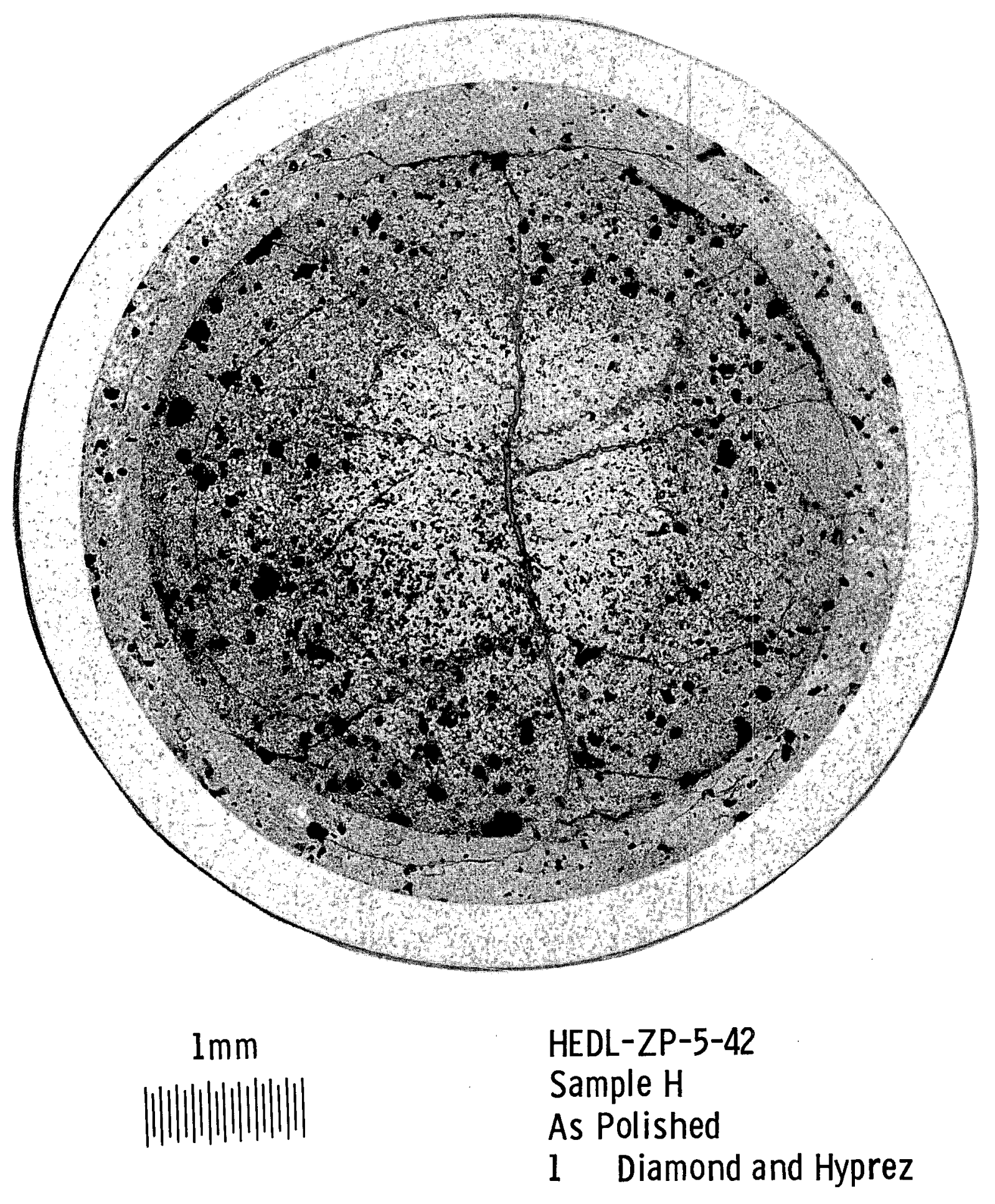

FIGURE 25. Microstructure of HEDL-ZP-5-42 Sample H. Neg 7812109 


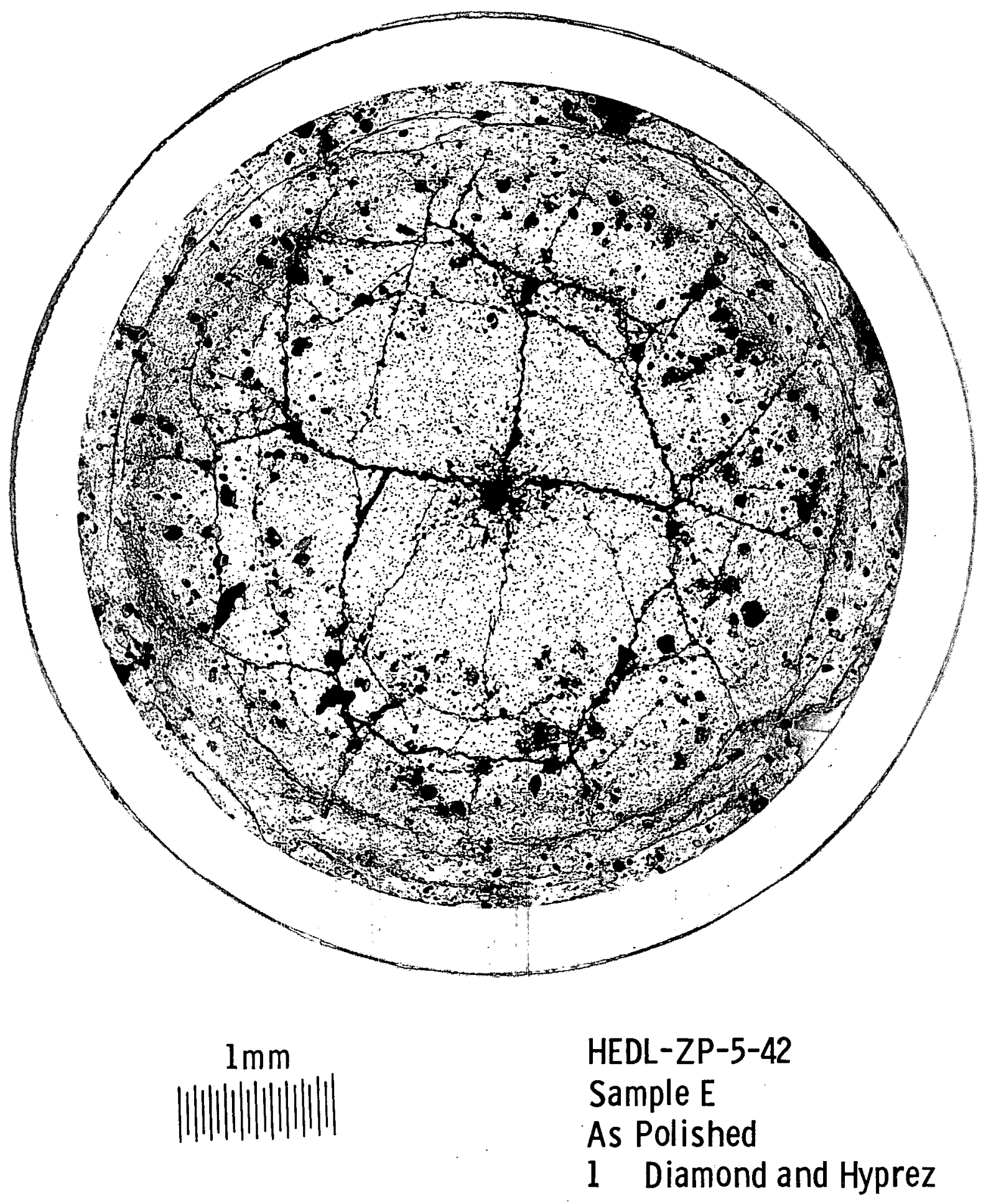

FIGURE 26. Microstructure of HEDL-ZP-5-42 Sample E. Neg 7810290 


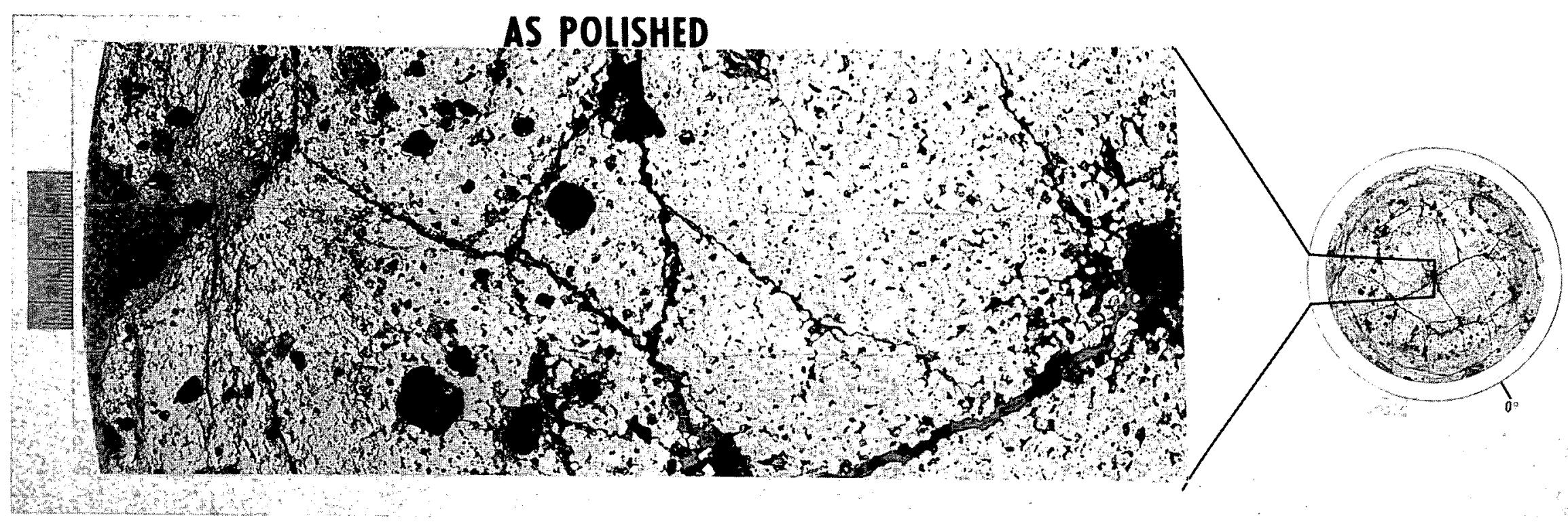

7907195-1

HEDL-ZP-5-42

Sample E

FIGURE 27. Microstructure of HEDL-ZP-5-42 Sample E - Radial Strip. 
an outer ring of fuel approximately $0.4 \mathrm{~mm}$ to $0.6 \mathrm{~mm}$ (16 to $24 \mathrm{mils}$ ) wide which appeared very dense except for some as-fabricated porosity. A continuous intergranular phase, presumed to be sodium-fuel reaction product based on the RBCB-6 results, ${ }^{(6)}$ was adjacent to fuel cracks and appeared only in this outer ring. The thickness of the grain boundary phase decreased with distance from the fuel cracks. The intergranular attack was much less extensive in $Z \mathrm{P}-5-42$ (RBCB-7) than in ZP-8-24 (RBCB-6).

Sodium-fuel reaction in the inner fuel core appeared as a few dispersed rounded islands not showing any associated intergranular attack. An abrupt boundary of intergranular reaction product was associated with the transition in fuel structure (Figure 28 and 29). The transition in morphology was strikingly evident around some of the pores located in the transition region (Figures 30 and 31). A circumferential shutdown crack separated the outer ring from the inner fuel core in the section from the lower slit extension. The sodium-fuel reaction product formed a layer on the outermost surface of the fuel. The layer had a structure less appearance and was a few hundredths of a millimeter thick. The layer was discontinuous around the fue 1 circumf erence.

Section $L$ (Figures 20 and 21 ) was $30.6 \mathrm{~cm}$ from the $B 0 F$. The reaction product distribution in the fuel-cladding gap was discontinuous. Little reaction product was evident overa 11, varying from $0.01 \mathrm{~mm}$ to $0.03 \mathrm{~mm}$ in thickness. Intergranular reaction was very limited and closely followed existing fuel cracks. Radial cracks had opened in the outer ring of the fuel. Intermittent segments of a circumferential crack were evident. A large number of artifacts-were introduced during metallographic preparation of this specimen, especially in the fuel center. Section $L$ was assumed to be atypical of the other sections in $2 P-5-42$.

Section $J$ (Figure 22, 23 and 24) was along the lower slit extention $(27.0 \mathrm{~mm}$ from $B O F)$. The reaction product layer in the fuel-cladding gap was discontinuous. The layer ranged from less than $0.01 \mathrm{~mm}$ to $0.04 \mathrm{~mm}$ thick. Intergranular reaction in Section $\mathrm{J}$ was more extensive than in Section $L$. 


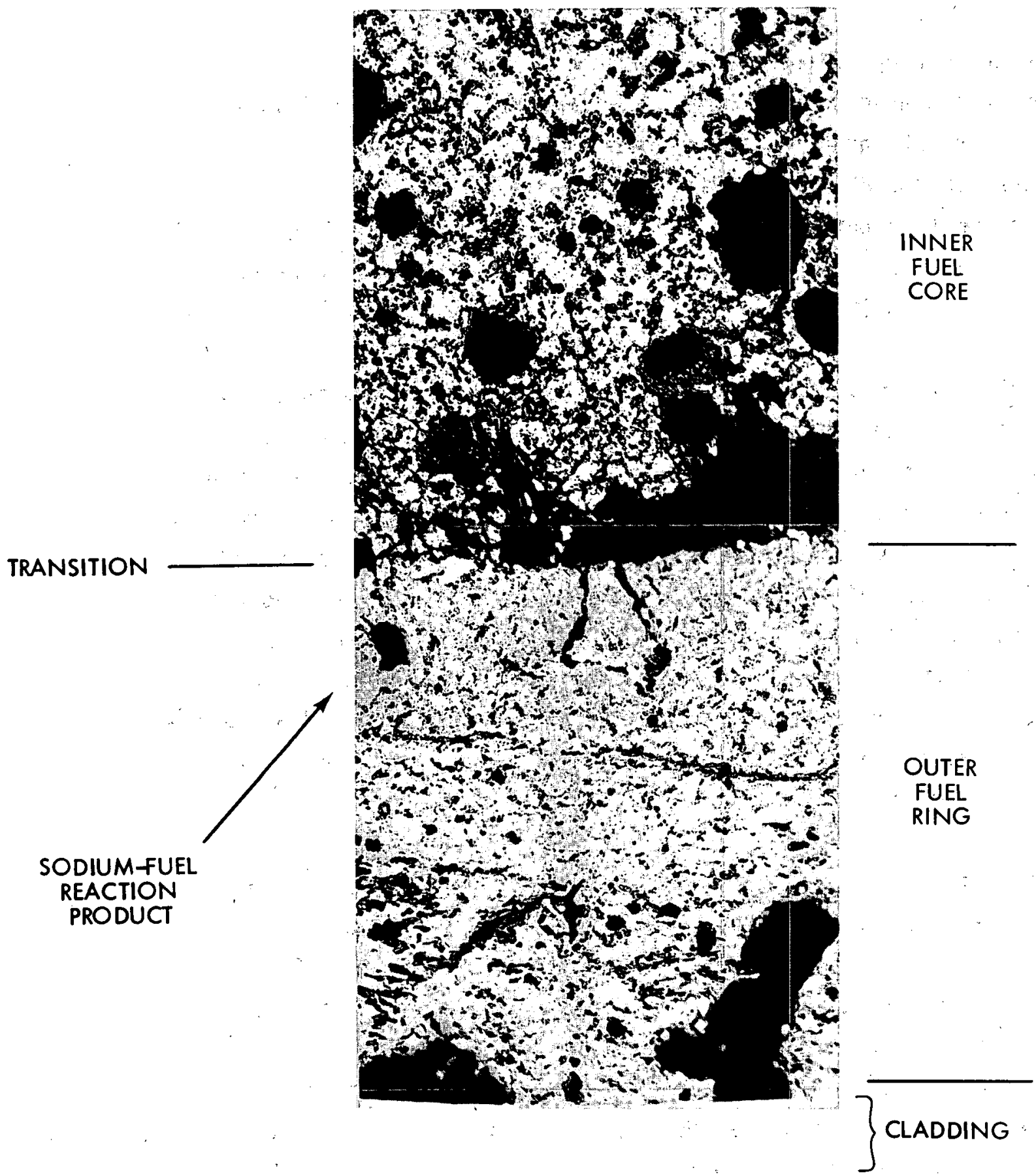

HEDL 7908-020.8

FIGURE 28. Transition Zone in the Fuel from ZP-5-42 Sample H Showing Transition in Fuel Structure and Morphology of Sodium-Fuel Reaction Product. Neg 7909733-21 


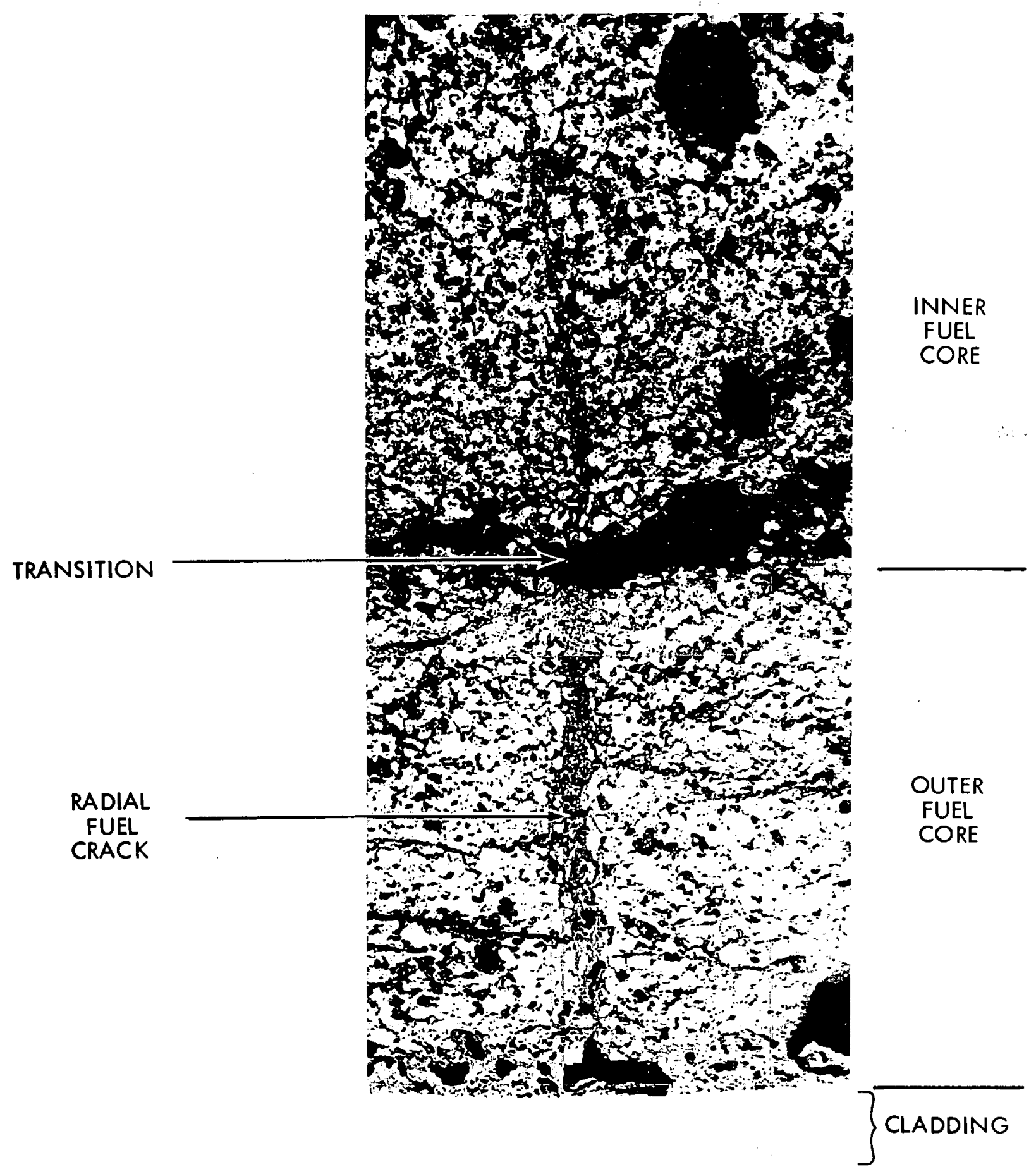

HEDL $7908-020.6$

FIGURE 29. Transition Zone in the Fuel from ZP-5-42 Sample H Showing Transition in Fuel Structure and Morphology of Sodium-Fuel Reaction Product Along a Radial Fuel Crack. 


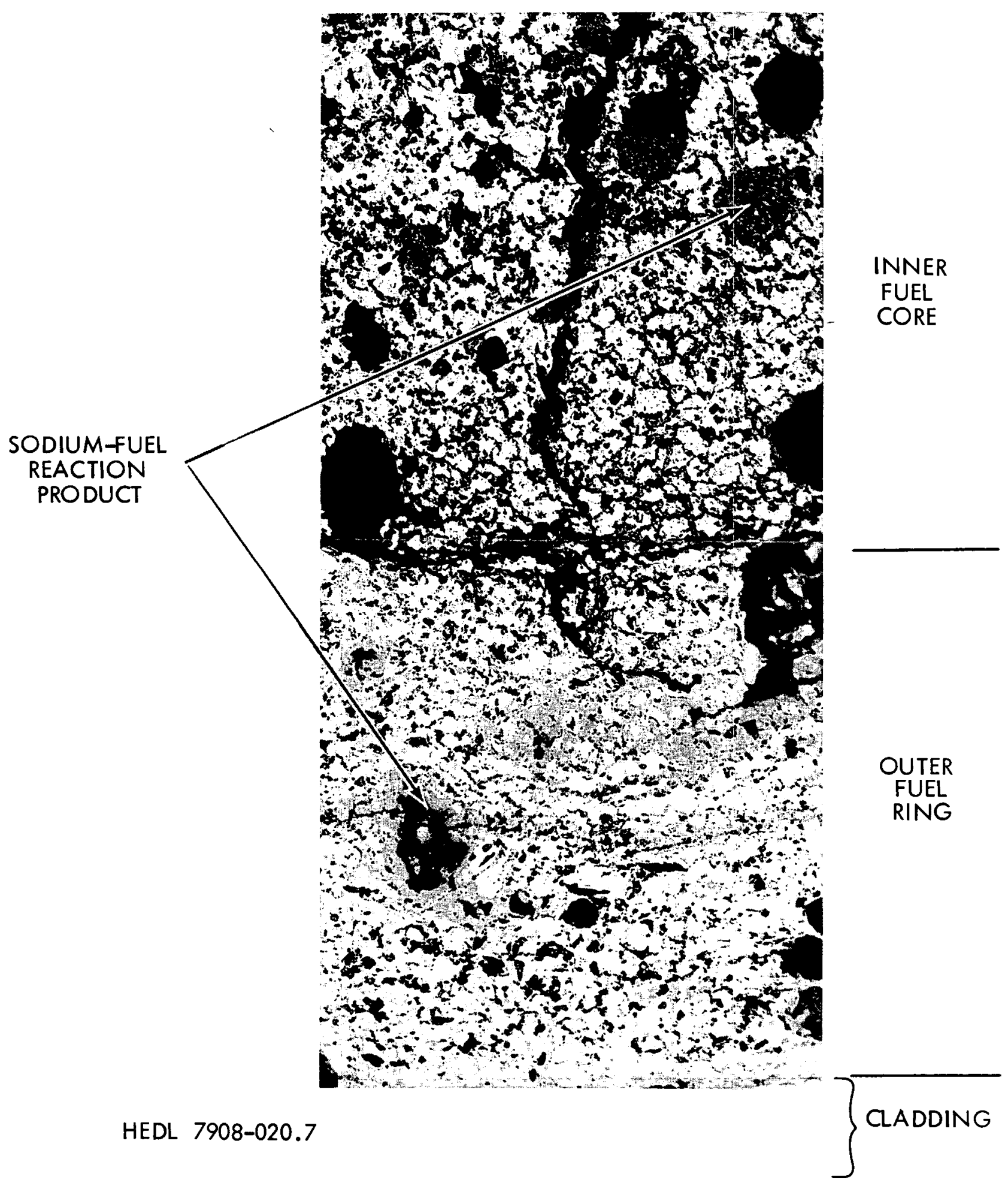

FIGURE 30. Sodium-Fuel Reaction Product Morphology Around Pores in the Dense Outer Fuel Ring and Inner Fuel Core Areas of ZP-5-42 Sample H. Some intergranular reaction product is evident only in the outer fuel ring. 


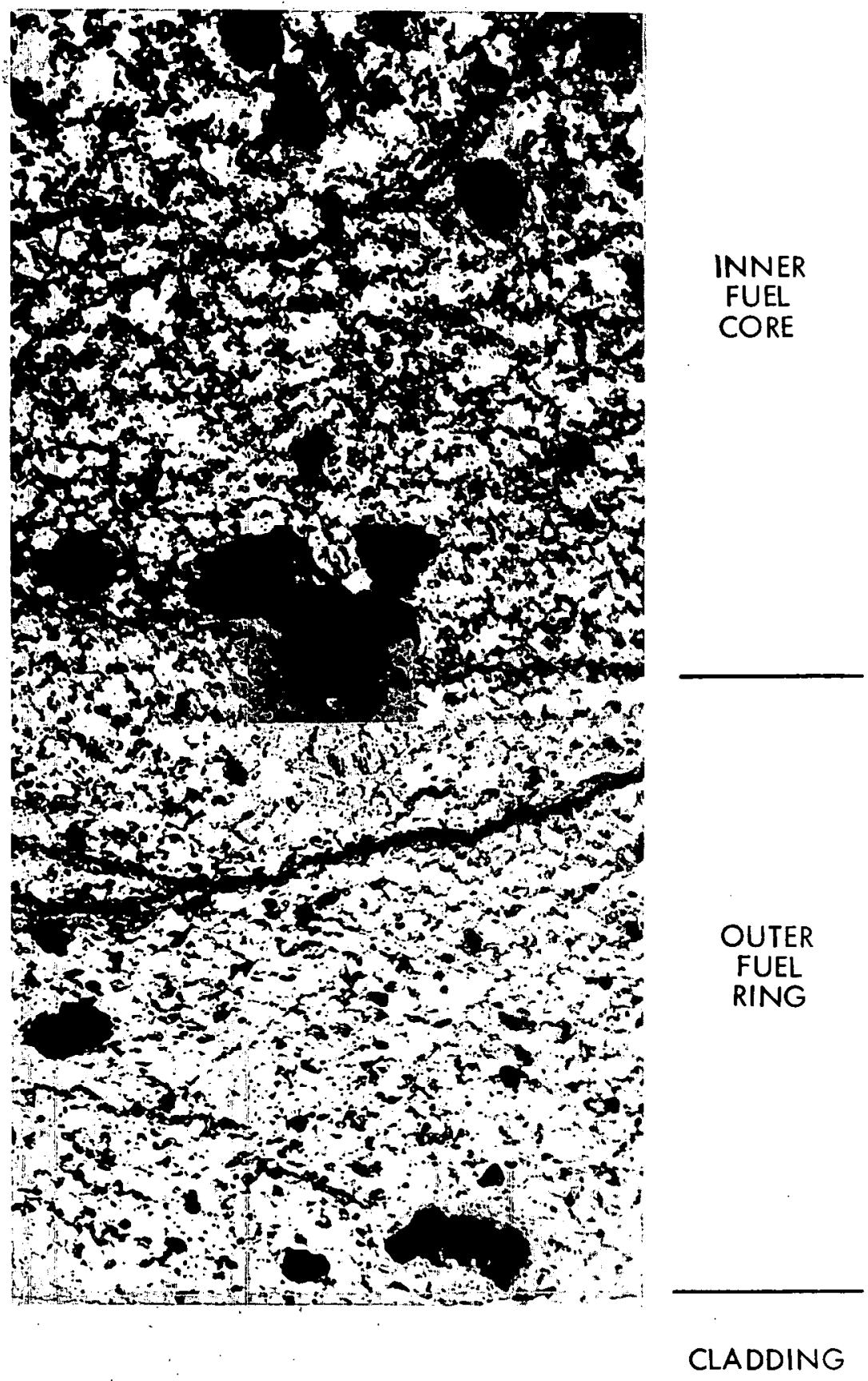

HEDL 7908-020.4

FIGURE 31. Sodium-Fuel Reaction Product Morphology Around a Pore Bridging the Abrupt Transition in Fuel Structure of ZP-5-42 Sample H. 
Intergranular reaction product formation occurred adjacent to existing fue 1 cracks in the outer fuel ring. The greatest concentration was adjacent to the circumferential crack. Radial shutdown cracks opened in the outer rim of the fuel. A well-developed circumferential crack was present. Intergranular reaction product was formed on both sides of the circumferential crack.

Section H (Figure 25) was unique in that it had an exceptionally sharp transition in fuel structure that coincided with the inner boundary of the intergranular reaction product. Section $H$ was from an area below the slit extension where the $c l$ adding was still intact $(25.0 \mathrm{~cm}$ from BOF). The reaction product layer in the fuel-cladding gap was discontinuous and generally less than $0.01 \mathrm{~mm}$ thick. However, there was a local area where it was $0.03 \mathrm{~mm}$ to $0.04 \mathrm{~mm}$ thick. The extent of intergranular reaction was comparable to that in Section $\mathrm{J}$ where it was restricted to and concentrated on the inside of the dense outer ring of fuel. This section did not exhibit either radial cracks in the dense outer fuel rim or circumferential fuel cracks of any significance.

Section $E$ (Figures 26 and 27) was farthest from the breach and was surrounded by intact cladding $(17.8 \mathrm{~cm}$ from BOF). Section $E$ had the longest path for sodium to travel to sustain the reaction. A negligible amount of reaction product was found in the fuel-cladding gap. The small quantity of intergranular reaction product occurred along existing fue 1 cracks in the outer fue 1 $r$ im and was distributed similarly to the reaction product in Section L. As in Section $H$, Section $E$ did not exhibit any radial fue 1 cracks in the dense outer fuel $r$ im or any circumferential cracks. The transition in fuel structure from the rim inward was gradual and similar to that observed in Section L.

\section{Water Wash Sample}

In ZP-8-24 gamma scan results and later visual observations during fue 1 pin sectioning indicated that sodium ingress had proceeded as $f$ ar up the pin as 
the top of the reflector. A 1-cm long section from this area was washed with water and the water analysis showed the presence of sodium and fission products.

In 2P-5-42 the visual indication of sodium at the top of the reflector was less obvious. However, a comparable pin section was washed with water and the water analyzed using an improved spectrographic technique. Cesium was found in the water wash. The concentrations of cesium and sodium were an order of magnitude smaller for the ZP-5-42 sample but the ratios of Cs:Na were nearly the same.

\section{Fuel Pin Cladding}

Detailed microstructural examination of the cladding was not essential because the defect was intentional and the postirradiation examination revealed no indications of an abnormal operating environment. The significant metallurgical information to determine was the mode of crack propagation in the cladding rather than the cladding microstructure. The cladding in the transverse metallurgical sections was observed to have a normal appearance in the as-polished condition. The crack extended intergranularly through the cladding (Figure 32 ). 


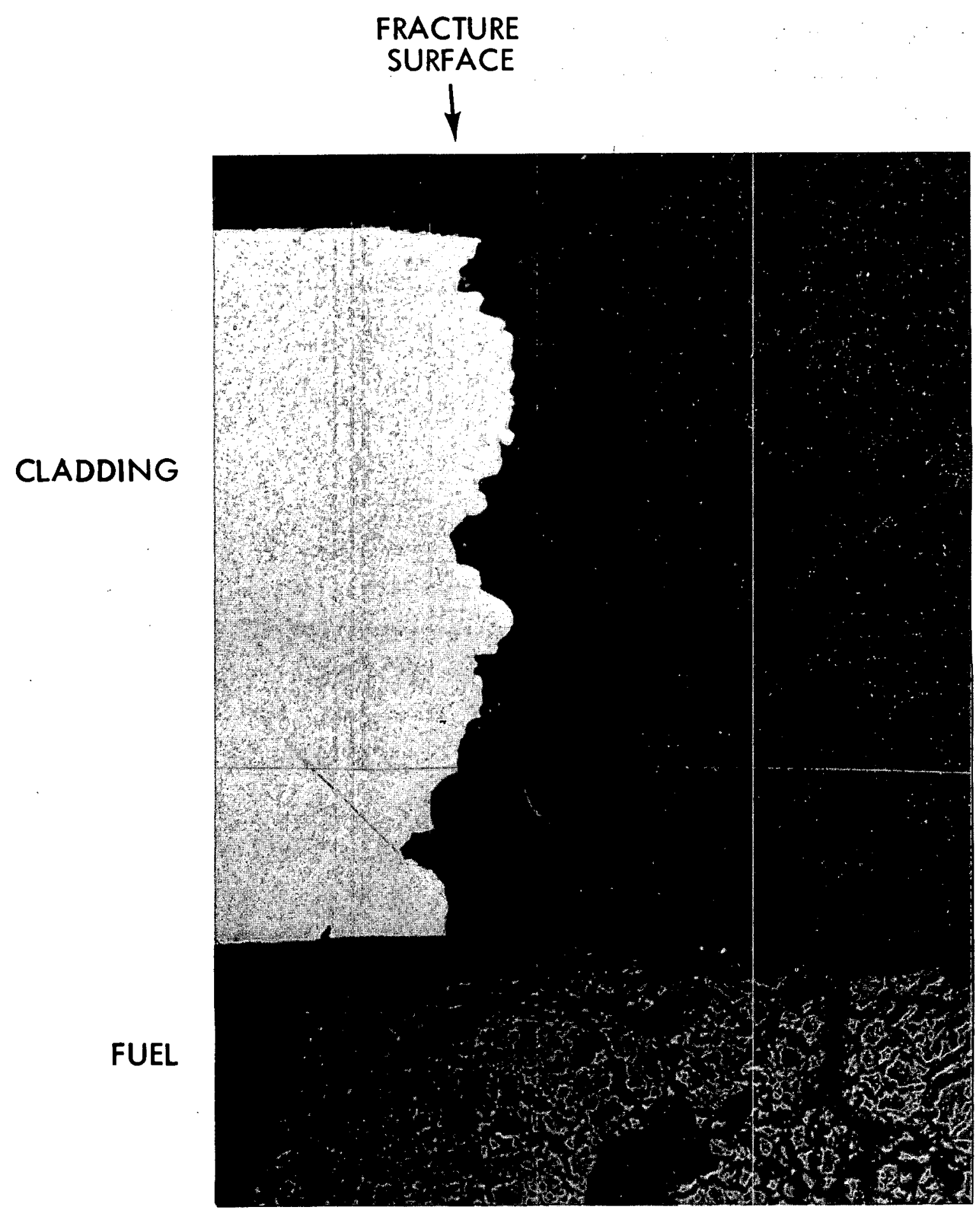

HEDL 7908-020.2

FIGURE 32. Cladding Fracture Profile from ZP-5-42 Sample J. Neg 7909733-18 


\section{DISCUSSION}

Visual examination of the RBCB-7 breached pin (ZP-5-42) and sibling pins indicated benign RBCB operation. No evidence of RBCB operation was observed other than the slit extensions in the predefected pin. The cladding breach area increased from $0.35 \mathrm{~cm}^{2}$ to $0.71 \mathrm{~cm}^{2}$ during the test.

Irradiation of ZP-5-42 demonstrated that DN detectors can easily monitor crack growth in a mixed-oxide fuel pin with fuel exposed to the sodium coolant. The test also demonstrated that during steady-state operating conditions crack development is a slow process and that reactor operators would have adequate time to take action before a safety hazard developed. It was also evident that crack development could occur under reactor shutdown or startup conditions with an RBCB pin in the reactor core. However, the factors contributing to crack development during shutdown or startup conditions are more numerous than those contributing to steady-state crack growth. These factors will be discussed later.

The mechanism of DN release is not obvious from this test. The nonlinear increase of DN signal with fission rate indicates that DN precursor release is not exclusively by a recoil mechanism. Fission product release by recoil is proportional to fission rate.

Excessive fuel pin swelling can reduce coolant flow and result in a temperature increase in the coolant and in the fuel pins adjacent to the affected coolant channels. However, an increase in the DN signal will accompany excessive fuel pin swelling. The cladding from RBCB-7 (ZP-5-42) had a fracture strain of $0.7 \%$. Any diametral cladding strain over the fracture strain is a geometric consequence of the opening of the cladding crack. Since fuel would be exposed to the sodium through the open crack, subsequent fuel pin diameter increases cannot impair subassembly performance without an increase in the DN signal. 


\section{A. RBCB AT CONSTANT POWER}

The gradual increase in DN signal at full power is attributed to the growth of cladding cracks at both ends of the slit. The driving force for these slit extensions is the time-dependent sodium-fuel reaction. Continued irradiation resulted in continued slit extension, predominantly in the downward direction. The extension in the upward direction stopped near the top of the fuel column because the upper $\mathrm{UO}_{2}$ insulators did not react with the sodium, analogous to the observed RBCB-6 breached pin behavior.

The maximum attainable slit width during steady-state operation is also determined by the extent of sodium-fuel reaction. The maximum diameter of RBCB-7 was comparable to that observed in the RBCB-6 breached pin, even though the RBCB-6 pin had three times the RBCB-7 steady-state exposure (7-1/2 hours vs $2-1 / 2$ hours, respectively). The comparable magnitudes of maximum swelling observed in both of these tests may be fortuitous or it may indicate that the reaction adjacent to the breach is nearing completion. This is not to say that reaction could not occur elsewhere along the length of the fuel column if sodium was available there.

The sodium-fuel reaction is a time-dependent chemical reaction that is controlled by the chemical potential of the reactants (sodium, oxygen, fuel) and the quantity of reactants available at the reaction site. Fission products and fuel structure can affect the reaction by affecting the chemical potential of the reactants and the rate of transport of the reactants, respectively. The reaction can be stopped by lowering the reaction temperature or by removing one or more of the reactants from the reaction site.

The extent of sodium ingress after a cladding breach occurs depends upon the proximity of a permeable fuel-cladding gap and interconnected fuel cracks to the open cladding crack. Sodium ingress occurred generally around the outer surface of the fuel, either along the fuel-cladding gap or along circumferential cracks near the fuel surface. Some sodium followed radial cracks. Sodium penetrated the fuel more deeply toward the top of the fuel column 
where the surface of the fuel-sectioning cuts changed from a normal to a smeared appearance. Sodium ingress was limited to the upper one-third of the fuel column and above. However, the amount of sodium ingress above the fue 1 was less than that in RBCB-6 (ZP-8-24). The sodium-fuel reaction was also much less extensive in RBCB-7 than in RBCB-6.

A comparison of the general ceramographic observations from RBCB-6 (ZP-8-24) and RBCB-7 (ZP-5-42) follows. Unlike the fuel sections in RBCB-6 (ZP-8-24), the as-fabricated fue 1 porosity was evident in all four ceramographic sections of RBCB-7 (ZP-5-42). The higher linear power produced a significant amount of grain growth in 2P-8-24. The metallic ingot distribution development depends on the number of free metal atoms available and on diffusion of these atoms to form ingots. The ${ }^{235} \mathrm{U}$ enrichment and central fuel temperatures in ZP-8-24 were higher than those in ZP-5-42, even though the ir irradiation times prior to RBCB operation were essentially the same. Consequent1y, it is reasonable to expect a more developed ingot distribution in the $Z P-8-24$ fue 1 . If the sodium-fuel reaction is independent on fuel composition and/or structure, it is reasonable to expect a difference in the character of the sodium-fue 1 reason product in these pins.

The intergranular sodium-fuel reaction product appeared only in the outer fue $1 \mathrm{rim}$, generally beyond a radius of $2.1 \mathrm{~mm}$ in both pins (see Figure 33 ). The intergranular reaction product occurred over a ring of fuel from $0.4 \mathrm{~mm}$ to $0.6 \mathrm{~mm}$ thick. In general, the reaction zone was thicker adjacent to the cladding slit extension. This resulted in an assymetric sodium-fuel reaction distribution about the pin axis. Examples of isolated rounded islands of reaction product also occurred in the outer rim but were more common in the inner fue 1 core.

The minimal depth of intergranular reaction product was uniform $(0.4 \pm 0.1 \mathrm{~mm})$ for all sections measured, measuring from the geometric center of the fuel. In a fuel section with a reaction zone of varying thickness, the greater penetration usually occurred near the breach site itself. For example, the reaction depth varied from $0.56 \mathrm{~mm}$ adjacent to 

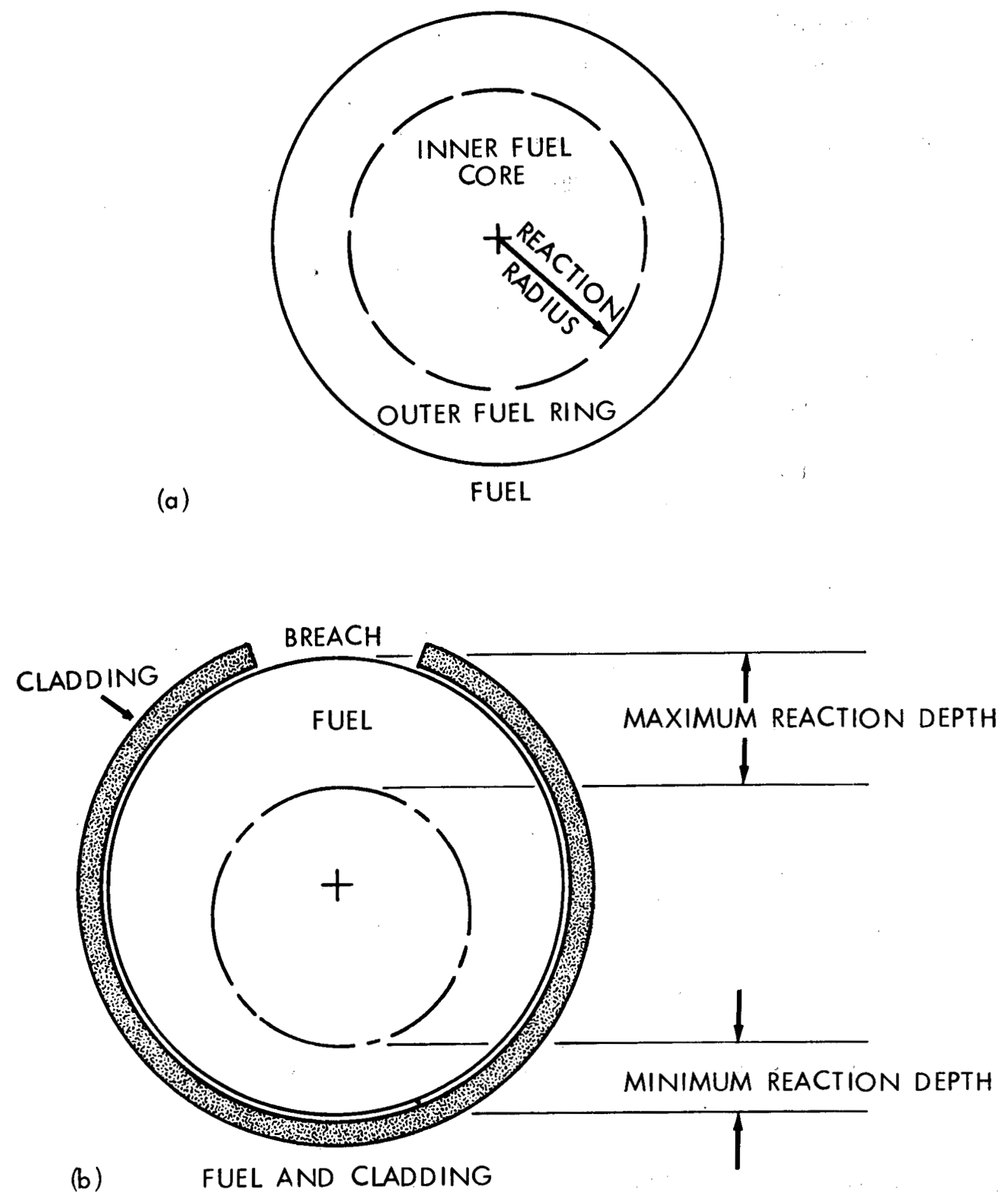

HEDL 7908-020.19

FIGURE 33. Schematic Diagram Illustrating the Terms Used to Describe the Sodium-Fuel Reaction Product Distribution: a) Fuel Structure and b) Reaction Depth. Neg 7909733-1 
the slit extension of $0.42 \mathrm{~mm}$ diametrically opposite the slit in ZP-5-42. This behavior was evident in both ZP-5-42-L and ZP-8-24-J. These sections intersect the slit and lower slit extension, respectively.

The formation of a 1 arge number of preparation art if acts observed in Section $L$ was probably associated with the presence of a large radial fue 1 crack. A second slit machining operation was required to remove the metal flash from the bottom of the cladding slit in ZP-5-42. Final visual inspection of the cleaned slit revealed axial fuel cracks as 1 arge as $0.16 \mathrm{~mm}$ wide (see Figure 5). A radial fuel crack $0.08 \mathrm{~mm}$ wide was observed directly under the saw-cut in the fuel in Section L (see Figure 20). A wide radial crack directly beneath the slit, penetrating deeply into the fuel, would have provided a direct path for sodium access to the fuel pellet interior after the pin was immersed in the reactor sodium. As the reactor power increased, the fuel could have reacted locally with sodium as soon as the fue 1 became hot enough. The reaction zone would have moved out from the center of the fuel with increasing pin power, resulting in reaction throughout the pellet interior. If the central pellet temperatures eventually exceeded the reaction product decomposition temperature, product decomposition could have occurred. This would seriously degrade the mechanical integrity of the fuel in that area. Degradation of fuel mechanical properties may be the reason for the extensive fuel fallout in this area during metallographic preparation of Section $L$.

A thicker reaction layer near the breach could be attributed to at least two factors: 1) time-dependent sodium ingress and 2) an assymmetric radial temperature distribution. An analysis of time-dependent sodium ingress must consider sodium flow through radial, axial and circumferential cracks, along fue 1 grain boundaries, through fuel grains and through the sodium-fuel reaction product itse If. Thus, to prove that the variation in-reaction layer thickness is caused by time-dependent sodium ingress is a very complex problem. An analysis using time-dependence may be a valid approach. However, an analysis using the fuel temperature profile may also be valid and less complex. A reaction layer of varying thickness at one axial location 
is not consistent with the assumption of a radially symetric temperature distribution. However, if the temperature of the fue 1 adjacent to the breach is lowered by direct contact with the reactor coolant, isotherms in the fuel would be shifted toward the fue 1 center. It is then possible that the reaction isotherm and the boundary of the intergranular reaction product would also shift toward the center of the fuel resulting in a thicker reaction layer being formed in this location.

\section{B. RBCB WITH POWER CHANGES}

A larger DN signal occurred during the RBCB-7 reactor restart than during the initial RBCB-7 reactor startup (at comparable power levels). During power changes, factors other than sodium-fue 1 reaction-product swelling can contribute to increase the DN signal.

A power increase develops a transient thermal environment in the pin. The thermal transient induces time-dependent strains in both fuel and cladding. If the transient is too rapid to allow strain accommodation, intermittent cladding crack growth and fuel cracking can occur. The rapid heating of the pin interior also causes sodium, drawn into the pin during reactor shutdown, and trapped fission gases to expand and to pressurize the pin. Sodium or fission gases ejected through the breach will carry along DN precursors from other regions of the pin in addition to those released from the fuel in the breach area. The ejection phenomenon will be less pronounced and occur less frequently once steady-state operation is achieved.

It is likely that a sufficient rapid power change will produce both a transient and a long-term increase in the DN signal. It is also likely that some breach en 1 argement occurred during the initial RBCB-7 reactor startup. Reactor power level changes or thermal cycling of an RBCB pin can cause pin degradation. More work is required to determine the effects of reactor power cycling on RBCB pin behavior and the use of controlled cycling to minimize pin degradation during load-following. 


\section{FUEL AND FISSION PRODUCT LOSSES}

There was no indication of fuel washout from the RBCB-7 fuel pin, either visually or from the fissile assay. No dislodged fuel particulate was detected during the forced argon cooling test in HFEF/N. These results suggest that the sodium fuel reaction product has adequate strength to permit longer irradiation without extensive fuel loss either in-reactor or during subsequent handling.

Some ( 1.0 to $1.5 \%$ of the cross-sectional area) fue 1. loss is apparent under the slit in ZP-5-42 Section L. The fuel area under the breach was covered with a layer of resin used to seal the breach at HFEF/N before shipping the pin to HEDL. It is difficult to determine exactly when and where the fuel was lost, other than at some time prior to sealing the breach. However, if the original slit profile is reconstructed from the photomosaic of Section L, it appears that the fuel was probably removed during the machining of the slit. (The slit reconstruction contained enough detail to show the machining burrs from the second slitting operation.) A second slit maching operation, penetrating the pin more deeply, was required to remove the metal flash left in the slit bottom after the initial machining. The width of the zone of fuel loss is comparable to the slit width produced by the saw and the profile of the loss area is comparable to the cut profile produced by the blade.

Comparison of pre- and postirradiation gamma scan profiles also confirmed that no fuel washout occurred. However, washout of sodium-soluble fission products such as ${ }^{137}$ Cs was strongly suggested. In any event, what losses occurred were negligible. No plutonium was detected in the reactor sodium and the increase in the fission product burden of the reactor coolant was acceptable. Reactor cover gas activity increases caused by fission gas releases from ZP-5-42 were maintained at acceptably low levels by CGCS. 



\section{CONCLUSIONS}

The irradiation and transfer of the RBCB-7 predefected fue 1 pins from the reactor into the hot cell were accomplished without detectable fuel loss. This accomplishment, together with the gradual change in DN signal during steady-state irradiation, supports increasing the DN signal limit for future mixed-oxide RBCB tests. There was no indication of an impending safety problem during the RBCB irradiation in spite of the fact that extensive sodium-fue 1 reaction occurred fairly rapidly.

The RBCB-6 and -7 results provide strong evidence that an increase in fue 1 pin diameter sufficient to restrict coolant flow in adjacent channels will also cause an enlargement of the cladding crack with an accompanying increase in the DN signal. The increase in DN signal is apparently gradual enough that operator action can be taken before a safety hazard is encountered. 


\section{REFERENCES}

1. R. Monson et a1., "Fission Product Control at EBR-II," Trans. ANS 27, pp. 822-823, 1977.

2. J. I. Sackett et al., "Preparation at EBR-II for Breached Element Operation," Trans ANS 27, pp. 823-825, 1977.

3. R. V. Strain et al., "Design and Use of the Fission Product Source at EBR-II," Trans ANS 27, pp. 825-826, 1977.

4. R. M. Fryer et al., "Safety-Related Considerations for Operation with Defected Elements in EBR-II," Proceedings of Fast Reactor Safety and Related Physics, pp. 615-624, November 1976.

5. D. F. Washburn et al., "Mixed-0xide Run-Beyond-Cladding-Breach Tests in EBR-II," Proceedings, International Conference on Fast Breeder Reactor Fuel Performance, pp. 100-111, March 1979.

6. D. C. Langstaff, et al., Results from the Run-Beyond Cladding-Breach Irradiation of a Predefected Fuel Pin (RBCB-6), HEDL-TME 79-23, Hanford Engineering Development Laboratory, Richland, WA, May 1979.

7. J. D. Berger, "High-Speed Slitter for Irradiated Stainless-Steel Tubing," Trans ANS 27, pp. 985-987, 1977.

8. R. G. Brown, Analysis of Heat Generating Blockages in CRBR Fuel and Radial Blanket Assemblies to Determine Detection Requirements, WARD-D-0119, Westinghouse Advanced Reactor Division, Madison, PA, September 1975.

9. E. E. Burdick, E. Fast and D. W. Knight, The Advanced Reactivity Measurement Facilities - A Description and Performance Evaluation, ID0-17005, Idaho National Engineering Laboratory, Idaho Falls, ID, 1974.

10. R. P. Colburn, et al., "Fission Product and Fuel Transport Behavior and Control," Sodium Technology Progress Report, Apri1-June 1978, HEDL-TME 78-91, pp. 16-19, Hanford Engineering Development Laboratory, Richland, WA, January 1979.

11. R. P. Colburn, et al., "Fission Product and Fuel Transport Behavior and Control," Sodium Technology Progress Report, July-September 1978, HEDL-TME 78-92, pp. 11-13, Hanford Engineering Development Laboratory, Richland, WA, January 1979.

12. E. A. Aitken, S. K. Evans, G. F. Melde and B. F. Rubin, "Reactions of Sodium with Mixed Oxide Fuel," ANS Proceedings of Conference on Fast Reactor Fuel Element Technology, pp. 459-478, New Orleans, LA, Apri1 1971. 


\section{DISTRIBUTION}

$\underline{\text { UC-79 (162) }}$

$\underline{\text { UC-79b }}$ (38), h (31)

DOE/RRT-HQ (2)

MaiT Stop B-107

Washington, DC 20545

Program Division Director

DOE/FFTFPO

Director

HEDL (34)

$\begin{array}{llll}\text { RE Baars } & \text { W/E-10 } & \text { DE Mahagin } & \text { W/JAD-7 } \\ \text { CM Cox } & \text { W/E-5 } & \text { LH Rice } & \text { W/C-15 } \\ \text { GE Culley } & \text { W/E-8 } & \text { WF Shee Ty } & \text { W/C-44 } \\ \text { RE Dah1 } & \text { W/JAD-7 } & \text { FR Shober } & \text { W/E-6 } \\ \text { DS Dutt } & \text { W/E-11 } & \text { DE Simpson } & \text { W/C-80 } \\ \text { EA Evans } & \text { W/JAD-6 } & \text { DF Washburn (2) } & \text { W/E-10 } \\ \text { JW Hagan } & \text { W/C-78 } & \text { ET Weber } & \text { W/A-63 } \\ \text { T. Hikido } & \text { W/E-9 } & \text { JW Weber } & \text { W/E-1 } \\ \text { RJ Jackson } & \text { W/E-7 } & \text { HH Yoshikawa } & \text { W/A-62 } \\ \text { NE Kenny } & \text { W/C-115 } & \text { Fuels \& Controls } & \text { W/E-2 } \\ \text { GA Last } & \text { W/JAD-6 } & \text { Trans Performance } & \text { W/E-10 } \\ \text { FE Holt } & \text { W/C-53 } & \text { Central Files (5) } & \text { W/C-110 } \\ \text { LA Lawrence } & \text { W/E-1 } & \text { Publ Services (2) } & \text { W/C-115 } \\ \text { RD Leggett } & \text { W/E-1 } & \text { Contract Admin } & \\ & & \text { SW Berglin } & \text { W/A-21 }\end{array}$

